\title{
The impact of economic policy uncertainty on carbon emissions: evaluating the role of foreign capital investment and renewable energy in East Asian economies
}

\author{
Yasir Khan ${ }^{1} \cdot$ Taimoor Hassan $^{2} \cdot$ Dervis Kirikkaleli $^{3} \cdot$ Zhang Xiuqin $^{1} \cdot$ Cai Shukai ${ }^{1}$ \\ Received: 8 September 2021 / Accepted: 7 October 2021 / Published online: 24 October 2021 \\ (c) The Author(s), under exclusive licence to Springer-Verlag GmbH Germany, part of Springer Nature 2021
}

\begin{abstract}
This study aims to investigate the relationship between carbon emissions $\left(\mathrm{CO}_{2}\right)$ and economic policy uncertainty for East Asian countries. During recent decades, climate change has become a severe issue globally. To our understanding, the impact of economic policy uncertainty $(E P U)$ on $\mathrm{CO}_{2}$ emissions has not been thoroughly studied in the environment-energy literature. To overcome this research gap, this study explores the link between $E P U, \mathrm{CO}_{2}$ emissions, foreign direct investment $(F D I)$, and renewable energy for the panel of four East Asian economies, namely, China, Japan, South Korea, and Singapore, from 1997 to 2020. We used second-generation econometric estimations to confirm cross-sectional dependence, cointegration, and stationarity among the selected variables. This study finds that economic policy uncertanity $(E P U)$, trade, and GDP have a positive correlation with carbon emissions. However, FDI and renewable energy consumption boost the quality of the environment of East Asian economies. The outcomes of the Dumitrescu-Hurlin panel causality estimation revealed twoway association between $\mathrm{CO}_{2}$ and economic policy uncertainty, $\mathrm{CO}_{2}$ and energy consumption, $\mathrm{CO}_{2}$ and economic growth, and $\mathrm{CO}_{2}$ and trade. Afterward, we use the FMOLS estimations for robustness check. Based on the inclusive outcomes, we draw substantial suggestions for decision-makers and urge them to consider the potential negative effects of $E P U$ on $C O_{2}$ emissions policies. In addition to this, if policymakers seek to simultaneously control $E P U$ and $\mathrm{CO}_{2}$ emissions, they should work out for alternate ways such as the use of green technology related to energy, foreign capital investment, and renewable energy consumption to mitigate $\mathrm{CO}_{2}$ emissions.
\end{abstract}

Keywords Economic policy uncertainty $\cdot$ Foreign direct investment $\cdot \mathrm{CO}_{2}$ emissions $\cdot$ Renewable energy $\cdot$ East Asia

JEL Classifications $\mathrm{F} 23 \cdot \mathrm{G} 18 \cdot \mathrm{Q} 43 \cdot \mathrm{Q} 53$

Communicated by Roula Inglesi-Lotz

Taimoor Hassan

taimoor@njust.edu.cn

Yasir Khan

yasirkhan@ahpu.edu.cn

Dervis Kirikkaleli

dkirikkaleli@eul.edu.tr

Zhang Xiuqin

merrysue@yeah.net

Cai Shukai

cskyeah@126.com

\section{Introduction}

This research work aims to highlight how economic policy uncertainty, foreign capital investment, and carbon emissions are interrelated. By doing so, we draw from the general

1 College of Industrial Economics, School of Economics and Management, Anhui Polytechnic University, Wuhu 241000, Anhui, China

2 Department of Management Science and Engineering, School of Economics and Management, Nanjing University of Science and Technology, Nanjing 210094, China

3 Department of Banking and Finance, Faculty of Economic and Administrative Sciences, The European University of Lefke, Lefke, Northern Cyprus TR-10 Mersin, Turkey 
Trends in $\mathrm{CO} 2$ emissions

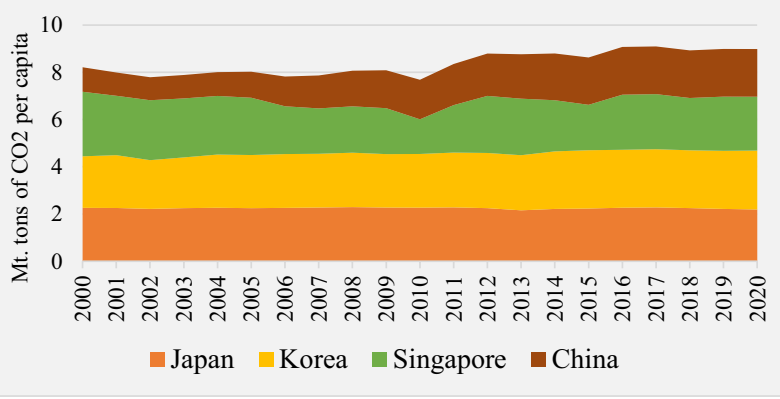

Fig. 1 Trends in the $\mathrm{CO}_{2}$ emissions in East Asian countries. Source: World Bank Indicators. https://databank.worldbank.org/reports.aspx? source $=$ world-development-indicators

literature on the economic policy uncertainty $(\mathrm{EPU})-\mathrm{CO}_{2}$ emissions as well as the foreign capital investment-economic policy uncertainty-renewable energy-related relationship. Research scholars and policymakers have shown keen importance in $E P U$ and its influence on economic activity.

The interrelationship between $E P U$ and $\mathrm{CO}_{2}$ emissions investigated by many research scholars (Abbasi \& Adedoyin, 2021; Anser et al. 2021; Jiang et al., 2019) determined that $\mathrm{CO}_{2}$ emissions are primarily dependent on the utilization of different sources of energies. Despite the fact, this phenomenon is somewhat obfuscated due to the latest prioritization and development of green advancement in numerous countries (Baek, 2015). A recent study proposed by Appiah (2018) found a multivariate Granger causal link between $\mathrm{CO}_{2}$, energy consumption, and economic growth, energy in Ghana. The interrelationship between $\mathrm{CO}_{2}$ emissions and economic growth may alternatively be conceptualized from the viewpoint of the $E K C$ hypothesis. The $E K C$ assumption describes that economic growth would commence the environmental coequality in the long run (Shahbaz et al., 2017a, b). However, a study conducted by Jiang et al. (2019) found that EPU is the key factor that has a significant impact on $\mathrm{CO}_{2}$ emissions not only in the aggregate economy but also within different manufacturing firms' sectors. Moreover, we also verify the impeding influence of economic policy uncertainly over the transformation of environment-friendly (carbon mitigation) technology investments. In addition, Anser et al. (2021) reveal the Granger casual relationships are both indigenous between $\mathrm{EPU}$ and $\mathrm{CO}_{2}$ emissions. Figure 1 illustrates trends in the $\mathrm{CO}_{2}$ emissions in East Asian countries from 1997 to 2020.

Many studies have explored the determinants of $\mathrm{CO}_{2}$ emissions in East Asia such as China, Japan, South Korea, and Singapore. The price effect and income level were added within the environmental Kuznets curve (EKC) model along with numerous control variables such as trade openness, FDI, financial development, technology transfer, and urban population. The findings of Sun et al. (2021) show that Chinese cities' $\mathrm{CO}_{2}$ emissions are among the top four cities' studies and are much higher when compared to the other sample cities in Japan and South Korea. Chongqing, Incheon, Tianjin, and Shanghai were the top four cities with the highest carbon intensity. Moreover, some research have focused on the updating and establishment of $\mathrm{CO}_{2}$ emission inventories (F. Yang et al., 2016), i.e., Japan prefectural emission accounts (Long et al., 2020), the China $\mathrm{CO}_{2}$ emission accounts (Shan et al., 2018), and GHG emissions from megacities in South Korea (Marcotullio et al., 2012).

The present paper aims to extend one more step to the previous research work investing the causal links among $E P U$, $\mathrm{CO}_{2}$ emissions, and foreign capital investment. We run the Granger causality test to investigate the causal links among $E P U, \mathrm{CO}_{2}$ emissions, renewable energy, and $F D I$, which helps us to understand the cross-sectional dependence (CSD) test and country-specific heterogeneity. Our study focuses on a total of four East Asian economies, namely, South Korea, China, Singapore, and Japan. Moreover, East Asia is the most populous region in the world where energy consumption is remarkably high. The pollution halo hypothesis signifies that multinational companies shift their clear and green technology from advanced economies to developing economies through FDI (Kim \& Adilov, 2012). Consequently, foreign direct investment $(F D I)$ can significantly contribute to decreasing the environmental pollution. Al-Mulali and Tang (2013) found the association between pollution, energy consumption, and FDI in the Gulf Cooperation Council (GCC) from 1980 to 2009. The key findings of their study support the pollution halo assumption and show that FDI is helping to reduce $\mathrm{CO}_{2}$ emissions, while energy consumption and $G D P$ growth are the major sources of pollution in $G C C$ economies. Mert and Bölük (2016) employed unbalanced panel data from 21 developing economies to explore the effects of $F D I$ and renewable energy consumption on $\mathrm{CO}_{2}$ emissions. Nevertheless, their findings point out that $F D I$ can enhance to bring clean and green technology and improve the quality of the environment that bolster the pollution haloes assumption. Moreover, a recent study by Mielnik and Goldemberg (2002) examine similar results in developing countries and endorsed that FDI harms $\mathrm{CO}_{2}$ emissions. Hao et al. (2020) and Zhang and Zhou (2016) used the province-level panel data and evidenced that FDI can help in reducing $\mathrm{CO}_{2}$ emissions, therefore supporting the pollution halo hypothesis. In addition, numerous studies refuse both empirical assumptions explored that FDI does not influence $\mathrm{CO}_{2}$ emissions (Atici, 2012; Shaari et al., 2014). Figure 2 represents trends in the EPU in the East Asian countries from 1997 to 2020.

The current literature focuses that there is a correlation between economic policy uncertainty and $\mathrm{CO}_{2}$ emissions. However, we reshape this study by adding a new direction in the literature. This work examines the association between $E P U$, foreign capital inflow, and renewable energy to East 
Fig. 2 Trends illustrations of EPU in the East Asian countries. Source: fred.stlouisfed. org. https://fred.stlouisfed.org/ release/tables?rid $=279 \&$ eid $=$ $841689 \#$ snid $=841691$

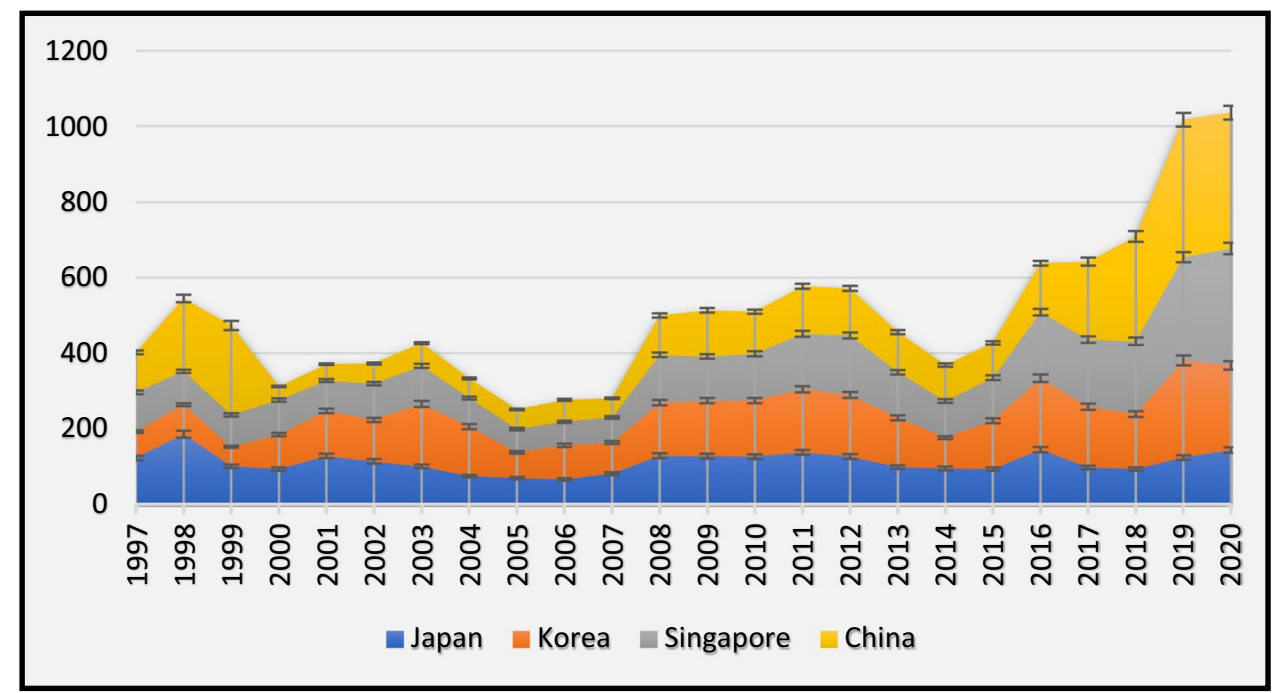

Fig. 3 Trends in FDI in the East Asian countries. Source: World Bank Indicator. https:// databank.worldbank.org/repor ts.aspx? source $=$ world-devel opment-indicators

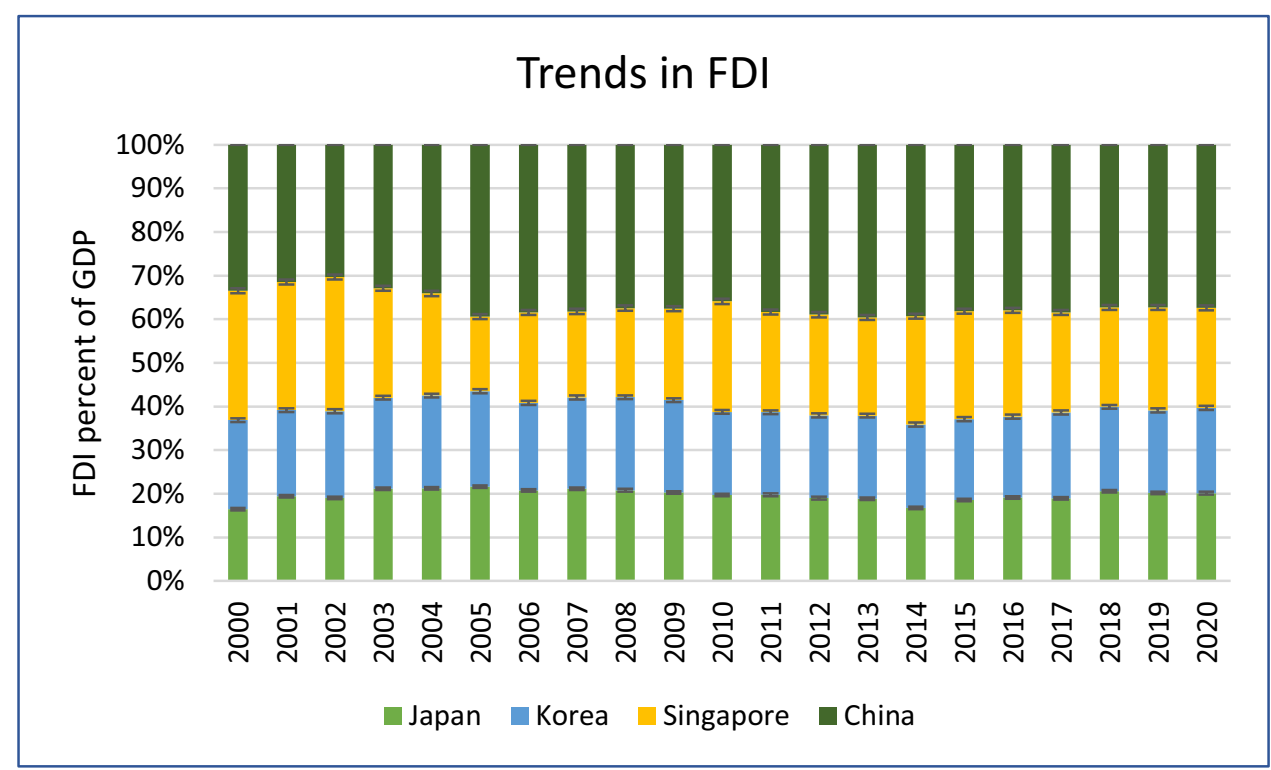

Asian countries. To our understanding, no study in the current literature examines the association between economic policy uncertainty and foreign capital inflow. This research study presented an empirical analysis based on the data collection of East Asia; we also understand that China, Singapore, Japan, and South Korea are the fastest growing polluted countries in the world.

Our study contributes several numbers of original contributions to the current literature. First of all, concentrating on the diminished aspect of $E P U$-foreign capital investment $(F D I)$ inflows-renewable energy nexus, the present study has not been explored in the previous studies. Second, by concentrating on foreign capital investment, our research study is adapting to consider the role of $E P U$ on the association between $\mathrm{CO}_{2}$ emissions and foreign capital investment. To the best of our ability, this work has been ignored in the previous literature. Third, contrary to the current research studies that are dependent on time-series data on every individual country, our study employs panel data that overcome the most important region in the world. Figure 3 shows trends in FDI in the East Asian countries from 1997 to 2020.

The rest of the paper is structured as follows: The related literary studies on the carbon emissions and its determinants are presented in the literature review section. The methodology section covers the employed econometric estimation techniques in this study. The outcomes of employed econometric models and estimations are presented and interpreted in the results and discussion section. The final conclusion and policy implications are drawn based on the obtained results and well presented in the conclusion and policy implications section. 


\section{Literature review}

The term economic policy uncertainty $(E P U)$ concept was first introduced by Baker et al. (2016) defining the economic policy uncertainty into three different sources of uncertainty: (a) the accumulation of a total number of federal/central tax code provisions set to outdate, (b) the capacity of government purchases and forecaster disagreement over future inflation, and (c) the frequency of news media references to monetary and fiscal policies. As proved by this novel index, the current literature contributions by scholars have hypothetically examined that economic policy uncertainty $(E P U)$ has negative influences both at the macro level such as economic growth and micro-level corporate investments.

The current literature examined the economic policy uncertainty known as the uncertainty concerned to government taxation, regulatory, environmental, fiscal, and monetary policies. Resultantly, these uncertainties led to market inconstancies and influence the economic outcomes, the environment in which economic brokers work. Latest studies explored the various effects of policy uncertainty on different economic activities such as (Bernal et al., 2016; Junttila \& Vataja, 2018) environmental pollution (Adedoyin \& Zakari, 2020; Pirgaip \& Dinçergök, 2020b), trade (Asiedu, 2006; Handley \& Limao, 2017), mergers and acquisitions (Bonaime et al., 2018), and investment (Gulen \& Ion, 2016; Liu \& Zhang, 2020).

To the best of our ability, the economic policy uncertainty $(E P U)$ directly affects carbon emissions through the "policy alteration effect" while "indirectly through the economic demand effect." A previous study investigated by Adedoyin \& Zakari (2020) utilized the Auto repressor distributed lag $(A R D L)$ and error correction $(E C)$ model to determine the association among $\mathrm{CO}_{2}$ emission, uncertainty in economic policy, and energy consumption by employing the panel data from 1985 to 2017 of the UK. The outcomes of their study reveal that uncertainty in economic policy in the short run plays a meaningful role in mitigating environmental pollution in the UK, while in the long run, the economic policy uncertainty (EPU) raises $\mathrm{CO}_{2}$ emissions. Jiang et al. (2019) employ panel Granger causality test to investigate the relationship between $E P U$ and $\mathrm{CO}_{2}$ emissions to examine the effects of institutional factors as a major contributor in increasing the level of $\mathrm{CO}_{2}$ emissions by employing US sectoral-level data. Based on their study, a Granger causality association was found between the US economic policy uncertainty $(E P U)$ and carbon emissions growth. Research scholars such as Pirgaip and Dinçergök (2020a) explored the links among the energy consumption, $E P U$, and carbon emissions employing bootstrap Granger causality test by panel data set from 1998 to 2018 in Group-7 economies which reveals the existence of causal links between various economies within the Group-7.

Economic policy uncertainty $(E P U)$ is described as the uncertainty correlated with government policies, specifically monetary and fiscal policies that influence an economic activity in which firms operate (Pirgaip \& Dinçergök, 2020b). All across the globe, economic and political uncertainty takes place due to worldwide instabilities that have an inimical influence on economic operations (Blattman \& Miguel, 2010; Guidolin \& La Ferrara, 2010). For instance, in 2003, the second Gulf conflict induced economic ambiguity in the global market (Rigobon \& Sack, 2005). Currently, Covid-19 has constituted substantial uncertainty all over the world (Altig et al., 2020; Baker et al., 2020). The EPU has significantly affected business activities, which resultantly influence business decisions. Moreover, EPU may affect consumption and investment spending, thereby affecting $\mathrm{CO}_{2}$ emissions. The decrease in consumption of renewable energy and as well as research and development because of higher economic policy uncertainty may affect a stimulation in $\mathrm{CO}_{2}$ emission. This demonstrates as the environment correlates with the manufacturing of business entities. Economic policy uncertainty may likely influence $\mathrm{CO}_{2}$ emissions (Al-Thaqeb \& Algharabali, 2019). The current research figures out the influence of $E P U$ on carbon emissions through direct sustainable public policies that may prompt or deter environmental quality. Hassan et al. (2021) found that less political risk helps to degrade carbon emissions while some other certain factors such as economic, composite, and financial uncertainty increase $\mathrm{CO}_{2}$ emissions.

The literature on $\mathrm{FDI}-\mathrm{CO}_{2}$ emissions has been documented by many scholars. The FDI effect on the environment has been reviewed in enormous studies (Abdouli \& Hammami, 2017) and found the influence of $F D I$ inflow and foreign trade on carbon emissions in Turkey (Haug \& Ucal, 2019); the links between foreign capital inflow and carbon emissions in MENA region from 1990 to 2015 (Shahbaz et al., 2019); the inter-link association between energy consumption and economic growth in the top 10 energy-consuming economies, namely, the USA, China, Japan, Germany, Russia, Canada, France, South Korea, and Brazil employing quantile on quantile estimation by Shahbaz et al. (2018); the possible consequences of foreign capital investment and relevant factors in association with environment considering the case of China (Zomorrodi \& Zhou, 2017); the impact of FDI inflows, energy consumption, and income on carbon dioxide emissions employing cross-sectional data of five ASEAN economies over 1981-2010 (Baek, 2016); and the influence of foreign capital investment inflows, GDP, exchange rate, and trade structure on China's $\mathrm{CO}_{2}$ emissions over 1982 to 2016 
utilizing the environmental Kuznets curve (EKC) hypothesis (Y. Zhang \& Zhang, 2018).

The previous literature contribution examined the major effect of $F D I$ on $\mathrm{CO}_{2}$ emissions. Al-mulali (2012) explores the effect of $F D I$ on $\mathrm{CO}_{2}$ emissions in the Middle Eastern countries using panel data from 1990 to 2009. Their result reveals that $F D I$ has an enormous contribution in increasing $\mathrm{CO}_{2}$ emissions. Researchers such as Tang and Tan (2015) explored the links between $F D I$ and $\mathrm{CO}_{2}$ emissions in the case of Vietnam from 1979 to 2009 and determined that FDI and $\mathrm{CO}_{2}$ emissions have a bidirectional causality association. The latest study by Khan and Bin (2020) reveals that $F D I$ inflow to the belt-and-road countries significantly raises the level of $\mathrm{CO}_{2}$ emissions. Other scholars such as Shahbaz et al. (2019) investigated the causal links between FDI and $\mathrm{CO}_{2}$ emissions in the MENA countries from 1990 to 2015, and the outcomes indicate that $\mathrm{FDI}$ positively affected $\mathrm{CO}_{2}$ emissions. In addition, a new determinant of $\mathrm{CO}_{2}$ mitigation and public-private partnership in energy introduced by Khan et al. (2020a, b) found that both public-private partnership investment in energy, imports, and GDP lead to increased consumption-based carbon emissions. Khan et al. (2020a, b) examine that exports, environmental innovation, and renewable energy consumption help abate consumptionbased $\mathrm{CO}_{2}$ emissions.

In contrast, the study of Sabir et al. (2020) shows that $F D I$ has a statistically significant and positive influence on environmental mitigation in South Asian nations. The latest research by Hao et al. (2020) suggests that a rise in FDI promotes a reduction in $\mathrm{CO}_{2}$ emissions. Investigating a sample for 20 developing countries by Mert and Bölük (2016) suggest that when foreign direct investment increases, energy intensity declines which helps to decrease the level of $\mathrm{CO}_{2}$ emissions. Zhang and Zhou (2016) explore the relationship between $\mathrm{FDI}$ and $\mathrm{CO}_{2}$ emissions in the three regions of China, namely, eastern, central, and western, over 1995 to 2010 , and the results indicate that FDI can substantially enhance the reduction of carbon emissions through utilizing advanced technology. Moreover, previous studies confirm that the pollution-haven theoretical assumption is one of the most acknowledgeable hypotheses that bolster the connection between environmental pollution and FDI (Copeland \& Taylor, 1994; Walter \& Ugelow, 1979).

Pertaining to this assumption, multinational companies moved extensively polluting manufacturing industries to countries with less environmental ground rule to avert compliance with costly regulations in their own countries. Consequently, the developing nations are paying the highest costs in the form of health diseases, drought, hunger, melting glaciers, and deforestation from more environmental challenges and become pollution harbors. Baek (2016) investigated the effect of $F D I$, energy consumption, and income with $\mathrm{CO}_{2}$ emissions by employing $P M G$ model of dynamic panels on the ASEAN region from 1981 to 2010 support the pollution-haven hypothesis and showed that FDI had raised the level of $\mathrm{CO}_{2}$ emissions. Moreover, Pao and Tsai (2011) utilized the cointegration estimation to examine the links among $\mathrm{CO}_{2}$ emissions, energy consumption, FDI, and economic growth for BRIC nations from 2007 to 2018 and revealed the positive effect of $\mathrm{FDI}$ on $\mathrm{CO}_{2}$ emissions. Zhang and Zhang (2018) explored the importance of financial development in China's environmental degradation and pointed out that $F D I$ was widely used in carbon-intensive production techniques and enhanced $\mathrm{CO}_{2}$ emissions. In addition, the corresponding findings were revealed by other researchers (Sabir et al., 2020; Tang \& Tan, 2015).

Finally, China, Singapore, Japan, and South Korea are geographical neighbors and have a similar cultural background; however, there are substantial differences in development patterns owing to differences in the economic development stages. Many studies proposed that FDI, technology transfer, and renewable energy consumption are arguable, but our study includes these variables into the estimations of the empirical model. We also believe that a few studies are evaluating the impacts of economic policy uncertainty (EPU) on $\mathrm{CO}_{2}$ emissions. To the best of our knowledge, our study gives fresh evidence for the impacts of the EPU on $\mathrm{CO}_{2}$ emissions in the empirical literature.

\section{Research innovations and deficiencies}

The key innovations in our study are to explore the latest findings between economic policy uncertainty, $\mathrm{CO}_{2}$ emissions, and other repressors. As export-oriented markets, China, Japan, Singapore, and South Korea have a significant association between $E P U, \mathrm{CO}_{2}$, and trade. Our study findings discover that raising carbon emissions is accompanied by increasing $E P U$ in East Asian countries. The uncertain elements in environmental policies could animate carbon emissions in these four countries. In order to tackle down carbon emissions, the government bodies and policymakers should develop consolidated environmental and economic policies which may usher in clean and green renewable energy sources. Likewise, economic growth and trade ameliorate environmental pollution; if industrial pollution is receded, it would provide opportunities to obtain sustainable development objectives in the long term. Moreover, our results also reveal that foreign direct investments and renewable energy consumption are helpful to reduce carbon emissions which ultimately decrease environmental pollution. Furthermore, our outcomes show a causality link between $E P U, \mathrm{CO}_{2}$ emissions, and $\mathrm{FDI}$ as previous studies such as Pirgaip and Dinçergök (2020a) reported no precise arguments on the $\mathrm{CO}_{2}$ emissions-economic policy uncertainty $(E P U)$ causality association. 
Fig. 4 Linkage mechanism of $\mathrm{CO}_{2}$ emissions and observed variables

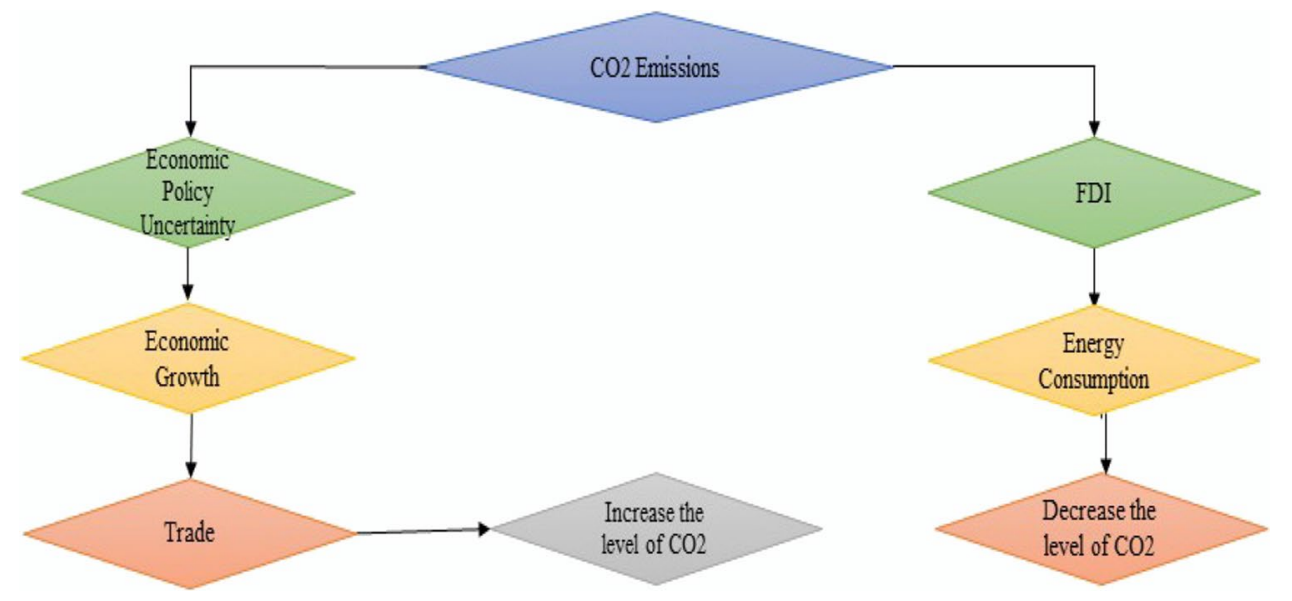

This research study can also be expanded to other regions, as many countries all over the world are experiencing economic policy uncertainty and carbon emissions. Taking this as an example, our study provides a piece of significant information and contributes to the literature which can be further enlarged all over the world by employing different data characteristics and econometric analysis. Figure 4 summarizes the expected impact mechanism of EPU and other observed variables on carbon emissions in selected economies.

Finally, regional and global concerns have been analyzed as inflection points that figure out the scale of economic policy uncertainty $(E P U)$. The reason behind this, as the economic policy uncertainty $(E P U)$ indicator, has its considerable factors created on tax provisions, disagreements by forecasters, and new references, which are considered to be avenues of conjecture for economic brokers. Developed on the illuminated motivation and related work in the introduction section, the current research work is more galvanized by the UN Sustainable Development Objectives (UN-SDGs 7 , 8 , and 14) expedition, which ultimately acquainted the selection of the data variables for various econometric techniques, and afterward, the following hypothesis has been designed:

\section{Research hypothesis}

- H1: Based on the cointegration links developed between $E P U, \mathrm{CO}_{2}$ emissions, renewable energy consumption, $F D I$, and trade, what is the relationship between the economic policy uncertainties (EPU) for East Asian countries over the selected period.

- H2: The study aims to find whether there is a negative or positive association among $\mathrm{EPU}, \mathrm{CO}_{2}$ emissions, renewable energy, and trade in the selected study areas (East Asian countries). Several researchers have examined the correlation between $\mathrm{CO}_{2}$ and economic growth pollution.

- H3: The renewable energy consumption that is clean and green energy consumption generates sustainability in the environment in the East Asian region. Historically, energy utilization has been determined as a signifying element for raising economic growth over the past years. Several empirical studies have validated this assumption such as the key function of the energy-generation growth assumption by Khan et al. (2021a, b), Bekun et al. (2019), and Alola et al. (2019). This concept leads to the establishment of further hypotheses.

- We explore the Granger causal links between $\mathrm{CO}_{2}$ emissions and other selected explanatory variables.

Therefore, governments and policymakers need to raise compactness and consistency in economic and environmental policies to gain an amicable environment in East Asian countries. Our findings propose that utilization of renewable energy is a proficient way to degrade environmental pollution that can ultimately proceed to boost sustainable development in the selected countries, namely, China, Singapore, Japan, and South Korea.

\section{Econometric methodology}

In the econometric methods section, we employed a series of different analyses such as unit root test, panel cointegration test, cross-sectional dependence tests, Granger causality tests and dynamic fixed effects, pooled mean group, and mean group estimations to examine the association between economic policy uncertainty and $\mathrm{CO}_{2}$ emissions. The detailed illustration modeling plan for this study is presented in Fig. 5.

\section{Theoretical background}

In this paper, we are interested to explore the causal linkage among observed variables and examine the change arising in carbon emissions due to any fluctuations in EPU and FDI; second, the carbon emissions-economic policy uncertainty 


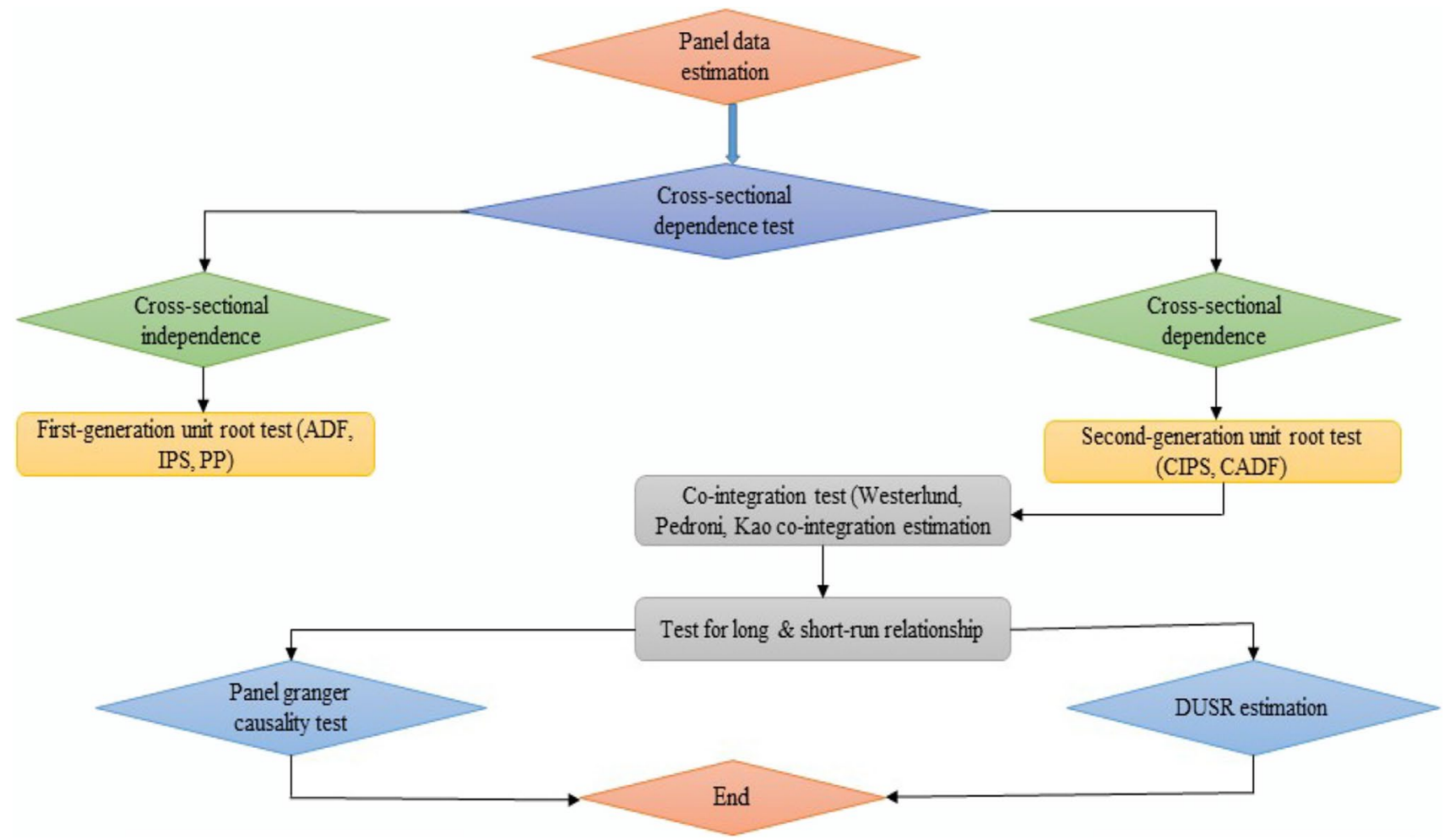

Fig. 5 Illustration of the study modeling plan

$(E P U)$ relationship; and third, research placing at the circle of these two study areas that mutually determine the connection between $\mathrm{CO}_{2}$ emissions, $E P U$, renewable energy utilization, and $F D I$.

The literature between $\mathrm{CO}_{2}$ and economic policy uncertainty (EPU) drawn from the guidance in Ozturk (2010) and Shahbaz et al. (2019) found that foreign direct investment has an extensive impact on $\mathrm{CO}_{2}$ emissions. Enormous literature on $\mathrm{CO}_{2}$ emissions and $F D I$ warns that $F D I$ is harmful to climate change and environmental regulation, specifically in areas fragile with environmental pollution-intense industries where the environmental principles are more lenient. According to the study developed by Ehigiamusoe and Lean (2019), they have researched this assumption in developed countries. In recent times, globalization has prompted structural alterations and overall economic shifts, which resultantly encouraged the linking of developing nations. Likewise, this study offers to validate the increase in pollution-intense manufacturing firms in East Asian economies through the authentication of the pollution-haven hypothesis.

\section{Conceptual framework}

We comprehensively describe the key innovation of the present paper in the introduction segment; this paper aims to highlight how carbon emissions, EPU, REC and FDI are interrelated. The latest study proposed by Khan et al. (2021a, b) examined that political uncertainty can severely cause the inflow of FDI in Pakistan. Therefore, we explore this relationship by outlining from general literature on the carbon emissions-EPU as well as on the $(F D I)-E P U$ relationship. This novel work is trimming to investigate the links among $E P U$, carbon emissions, renewable energy consumption, and FDI for East Asian economies. A consolidated and stable economic policy helps to mitigate carbon emissions which have a direct impact on environmental pollution. A strong and stable economic policy also provides a conducive environment for investors to establish the latest energy-efficient output. Our study explores that a variation and unstable economic policy increases the level of carbon emissions of major East Asian countries. The influence of economic policy uncertainty $(E P U)$ on economic exertion has been a key policy factor for scholars and policymakers. Therefore, fiscal or monetary regulatory uncertainties have frequently been linked with recessions back to the present (Bernanke, 1983; Friedman, 1995; Jin Guanghui, 2016; Rodrik, 1991). In addition, a recent literature contribution between $\mathrm{CO}_{2}$ emissions and EPU is reported in Table 1. 


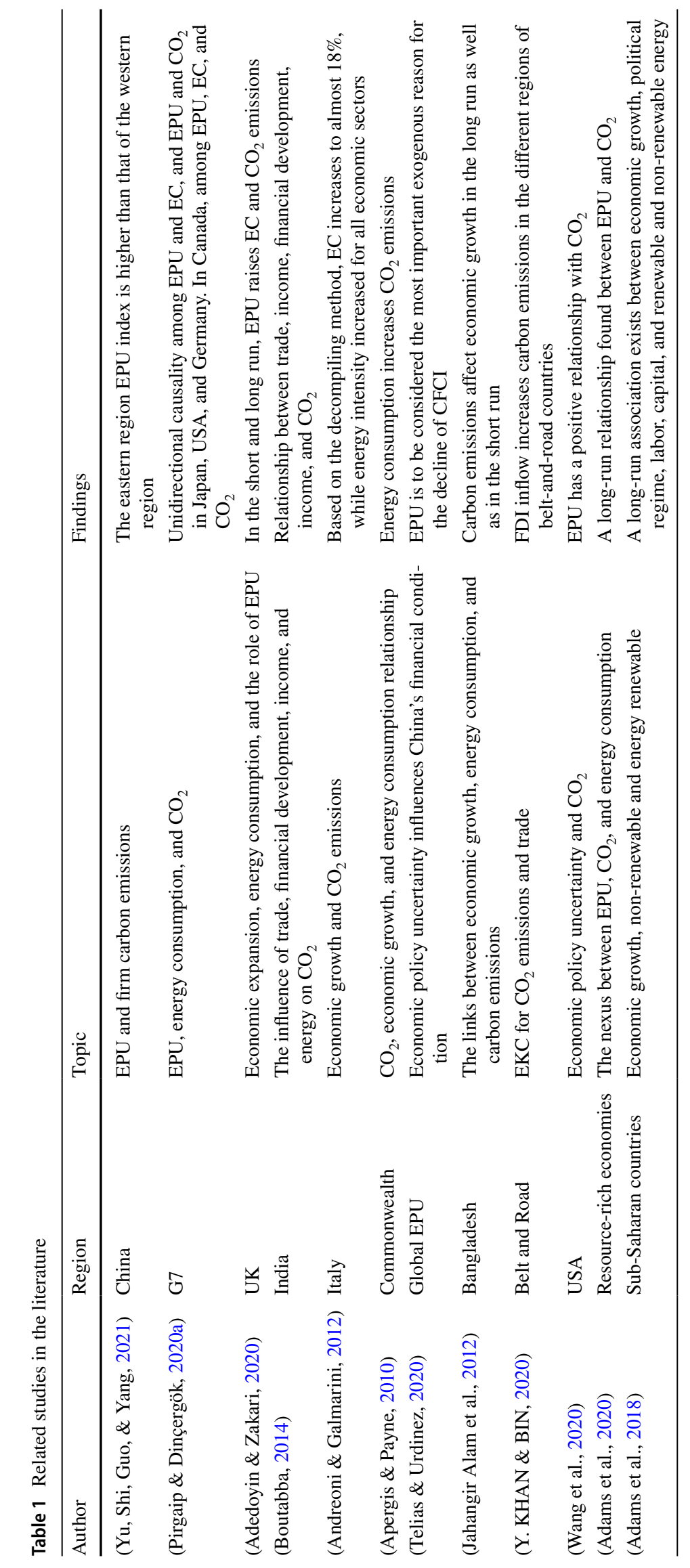


Table 2 Data description and sources

\begin{tabular}{|c|c|c|c|}
\hline Variables & Description & Unit & Source \\
\hline $\mathrm{CO}_{2}$ & Carbon emission & Metric tons of $\mathrm{CO}_{2}$ equivalent per capita & WDI \\
\hline EPU & Economic policy uncertainty & $\begin{array}{l}\text { Uncertainty raises potential concerns related to bias, newspaper } \\
\text { reliability, consistency, and accuracy (index) }\end{array}$ & $\begin{array}{l}\text { BP Sta- } \\
\text { tistical } \\
\text { Review }\end{array}$ \\
\hline FDI & Foreign direct investment inflow & FDI net inflow percent of the total GDP & WDI \\
\hline GDP & $\begin{array}{l}\text { Gross domestic product as a proxy of } \\
\text { economic growth }\end{array}$ & GDP current US\$ & WDI \\
\hline Trade & Trade openness & Net export and import trade current US\$ & WDI \\
\hline REC & Renewable energy consumption & Renewable energy consumption per capita & WDI \\
\hline
\end{tabular}

\section{Data specification}

In the present study, we investigate the association between economic policy uncertainty (EPU), FDI, renewable energy, and $\mathrm{CO}_{2}$ emissions by employing the annual data from 1997 to 2020 of four East Asian advanced economies. ${ }^{1}$ Moreover, the time duration selection of the study relies on the data availability. The primary source of the study data is from the World Bank Indicator (2020) and BP statistical review (BP, 2019) reported in Table 2. Recently, many studies have commonly used carbon dioxide emissions $\left(\mathrm{CO}_{2}\right)$ as an indicator of environmental degradation. We follow Pirgaip and Dinçergök (2020b) and take $\mathrm{CO}_{2}$ emission as a million tons of carbon dioxide. This data of the variable was downloaded from the BP statistical review ("BP Statistics", 2020). As mentioned in Sect. 2, we incorporated two main explanatory variables, foreign direct investment inflow $(F D I)$ and $E P U$, as determinants of carbon dioxide $\mathrm{CO}_{2}$ emissions. Following the previous studies (Adedoyin \& Zakari, 2020; Pirgaip \& Dinçergök, 2020b), we employ the economic policy uncertainty index $(E P U)$ as a proxy of policy uncertainty developed by Baker et al. (2016). ${ }^{2}$ Foreign direct investment $(F D I)$ inflows as a share of $G D P$ obtained from the world development indicators $(W D I)$ database. In addition, to investigate the impact of $E P U$ and $\mathrm{FDI}$ on $\mathrm{CO}_{2}$ emission, other control variables have been included in our empirical investigation. According to existing studies on this topic, energy consumption, $G D P$ growth, and trade openness can also affect $\mathrm{CO}_{2}$ emissions (Shahbaz et al., 2017a, b; Yang et al., 2020). Energy consumption is in a million tons of oil equivalent (Pirgaip \& Dinçergök, 2020a). Trade openness is described by total imports plus exports as a proportion of GDP (Halicioglu, 2009; B. Yang et al., 2020). In addition, GDP growth is defined by real GDP per capita in constant 2010 US\$

\footnotetext{
${ }^{1}$ Name of the East Asian economies: Japan, China, Singapore, and South Korea.

2 All economic policy uncertainty represents are available on https:// www.policyuncertainty.com.
}

(Shahbaz, et al., 2017a, b; Yang et al., 2020). All of these variables are sourced from the WDI database. Our final empirical model (after transforming all the concerning variables into $\log$ form) is as follows:

\section{Proposed model}

$$
C O 2=E P U, F D I, E C, G D P, \text { Trade }
$$

The proposed model is presented in Eq. (1). $\mathrm{CO}_{2}$ emissions are the response variable and denote as $\mathrm{CO}_{2}$ emissions per capita. Economic policy uncertainty $(E P U)$ is measured as the uncertainty boosts conceivable concerns associated with newspaper accuracy, reliability, consistency, and bias. Foreign direct investment defines as FDI net inflow (US\$); energy consumption (EC) describes as renewable energy consumption per capita (metric tons); GDP is gross domestic product (current US\$); trade openness is net export and import trade (current US\$).

$$
\begin{aligned}
\operatorname{lnCO2}_{i t} & =\alpha_{0}+\alpha_{1} \ln E P U_{i t}+\alpha_{2} \ln F D I_{i t}+\alpha_{3} \ln E C_{i t} \\
& +\alpha_{4} \ln G D P_{i t}+\alpha_{5} \ln \operatorname{Trade}_{i t}+\varepsilon_{i t}
\end{aligned}
$$

In Eq. (2), " $i$ " is the total observations of a cross-section of selected economies. " $t$ " is the total number of years; "CO2" is a natural logarithmic form of $\mathrm{CO}_{2}$ emissions per capita of carbon dioxide; " $E P U$ " represents economic policy uncertainty. " $F D I$ " is the foreign direct investment. " $R E C$ " illustrates renewable energy consumption; " $G D P$ " is estimated as the real GDP per capita; "Trade" is net export and import trade (current US\$). Finally, $\varepsilon_{i t}$ shows an error term.

\section{Summary statistics}

The statistics summary of all the selected variables in the present paper including response and explanatory variables are shown in Table 3. The outcomes demonstrate that the average $\log$ value of $\mathrm{CO}_{2}$ emissions is 8.64 and the SD is 2.93 in the full sample. This illustrates that the $\mathrm{CO}_{2}$ emission levels of the four selected countries were defiantly different. The economic policy uncertainty 
Table 3 Summary statistics

\begin{tabular}{|c|c|c|c|c|c|c|c|}
\hline Statistics & & $\mathrm{CO}_{2}$ & EPU & REC & FDI & GDP & TRADE \\
\hline \multirow[t]{6}{*}{ Full sample } & Mean & 2.0935 & 4.7290 & 4.3231 & 13.250 & 9.8029 & 26.022 \\
\hline & Median & 2.2470 & 4.7725 & 4.3039 & 11.992 & 10.133 & 26.573 \\
\hline & Max & 2.7338 & 5.8953 & 8.9052 & 24.435 & 10.963 & 27.559 \\
\hline & Min & 0.9740 & 3.5714 & -0.8128 & 2.8714 & 6.7197 & 22.882 \\
\hline & SD & 0.3991 & 0.4614 & 3.6935 & 9.8044 & 1.1832 & 1.4120 \\
\hline & Obs & 84 & 84 & 84 & 84 & 84 & 84 \\
\hline \multirow[t]{6}{*}{ Japan } & Mean & 2.2457 & 4.6522 & 1.4327 & 22.660 & 10.704 & 27.237 \\
\hline & Median & 2.2492 & 4.6146 & 1.3936 & 23.088 & 10.703 & 27.314 \\
\hline & Max & 2.2801 & 4.9758 & 1.8401 & 24.435 & 10.803 & 27.559 \\
\hline & Min & 2.1854 & 4.1868 & 1.2719 & 17.540 & 10.623 & 26.792 \\
\hline & $\mathrm{SD}$ & 0.0275 & 0.2365 & 0.1453 & 1.5221 & 0.0573 & 0.2842 \\
\hline & Obs & 21 & 21 & 21 & 21 & 21 & 21 \\
\hline \multirow[t]{6}{*}{ Korea } & Mean & 2.2874 & 4.8007 & -0.0458 & 22.879 & 9.9159 & 26.655 \\
\hline & Median & 2.2776 & 4.8758 & -0.1518 & 22.972 & 9.9723 & 26.821 \\
\hline & Max & 2.4941 & 5.5504 & 1.0431 & 23.608 & 10.263 & 27.316 \\
\hline & Min & 1.9857 & 3.9337 & -0.8174 & 21.746 & 9.4632 & 25.729 \\
\hline & $\mathrm{SD}$ & 0.1451 & 0.4012 & 0.4832 & 0.4577 & 0.2562 & 0.6000 \\
\hline & Obs & 24 & 24 & 24 & 24 & 24 & 24 \\
\hline \multirow[t]{6}{*}{ Singapore } & Mean & 2.2860 & 4.7476 & 8.5543 & 3.3305 & 10.475 & 24.387 \\
\hline & Median & 2.3330 & 4.6914 & 8.5306 & 3.3241 & 10.491 & 24.584 \\
\hline & Max & 2.8926 & 5.7367 & 8.9052 & 3.6429 & 10.963 & 25.235 \\
\hline & Min & 1.4684 & 4.1175 & 8.3565 & 2.8714 & 9.9793 & 23.075 \\
\hline & SD & 0.3147 & 0.4283 & 0.1165 & 0.1765 & 0.3846 & 0.7551 \\
\hline & Obs & 24 & 24 & 24 & 24 & 24 & 24 \\
\hline \multirow[t]{6}{*}{ China } & Mean & 1.6040 & 4.8027 & 7.3181 & 3.7595 & 8.0006 & 25.668 \\
\hline & Median & 1.7075 & 4.7572 & 7.4093 & 3.7712 & 8.2025 & 26.224 \\
\hline & Max & 2.0225 & 5.8953 & 7.7127 & 3.8646 & 9.0855 & 27.079 \\
\hline & Min & 0.9423 & 3.5714 & 6.7046 & 3.5745 & 6.4128 & 22.882 \\
\hline & SD & 0.4068 & 0.6390 & 0.3746 & 0.0886 & 0.9378 & 1.3907 \\
\hline & Obs & 20 & 20 & 20 & 20 & 20 & 20 \\
\hline
\end{tabular}

Table 4 Correlation matrix

\begin{tabular}{lccllll}
\hline Variables & $\mathrm{CO}_{2}$ & EPU & EC & FDI & GDP & Trade \\
\hline $\mathrm{CO}_{2}$ & 1.00 & & & & \\
$\mathrm{EPU}$ & $0.469 * * *$ & 1.000 & & & \\
$\mathrm{EC}$ & $-0.377 * * *$ & -0.053 & 1.000 & & \\
$\mathrm{FDI}$ & $0.474 * * *$ & 0.096 & $-0.979 * * *$ & 1.000 & & \\
$\mathrm{GDP}$ & $0.828 * * *$ & $0.414 * * *$ & $-0.308 * *$ & $0.450 * * *$ & 1.000 & \\
Trade & $0.480 * * *$ & $0.446 * * *$ & $-0.683 * * *$ & $0.731 * * *$ & $0.343 * * *$ & 1.000 \\
\hline
\end{tabular}

$*, * *$, and $* * *$ denote the significance level.

(EPU) average log value is 125.14 and its SD is 63.14 respectively. This outcome indicates that the economic policy uncertainty $(E P U)$ of the four countries illustrated a significant disparity from 2000 to 2020, which can also confirm the maximum value (363.35) and minimum value (35.57). Moreover, the average log value of $F D I$ is 4.98 while the SD is 7.73 . The summary statistics are divided into a full sample and calculated for every country. The
GDP average log value accounted for 2678.9 and the SD was 1773.4 , respectively.

\section{Correlation statistics}

The outcomes of correlation statistics are reported in Table 4 . The correlation statistics show that all the selected variables have a significant and positive relationship with 
each other. The values obtained from the correlation estimation are as follows: economic policy uncertainty $\left(0.4695^{* * *}\right)$, energy consumption $(-0.0534 * * *)$, foreign direct investment (FDI) ( $\left.-0.9797^{* * *}\right), G D P\left(0.4504^{* * *}\right)$, and trade $\left(0.4345^{* * *}\right)$ reported respectively. The result illustrates the positive correlation between economic policy uncertainty, $\mathrm{CO}_{2}$ emissions, $\mathrm{GDP}$, energy consumption, foreign direct investment, and trade. On the other hand, a negative and significant correlation reveals between economic policy uncertainty $(E P U)$ and $\mathrm{CO}_{2}$ emissions. Moreover, the result from statistical correlation suggests that uncertainty in economic policy significantly affects $\mathrm{CO}_{2}$ emissions and FDI. Therefore, the pair-wise correlation among the variables partially indicated that there is a possible connection between economic policy uncertainty and other repressors. Nonetheless, to further explore the relationship between all the selected variables, we conduct various statistical estimations to prove our hypothesis of the study. Therefore, the outcomes of further analysis are reported in the next section of the paper.

\section{Panel unit root tests}

Panel unit root test is an essential econometric test for investigating the data stationarity. In our study, we found that our data have the issue of cross-sectional dependence, and we are unable to use the unit root tests of first generation because it can lead to biased results. Therefore, to handle this issue, we used the second-generation advanced unit root test to evaluate the stationary of the data in the panel of four advanced developing economies. We employed (Pesaran, 2007) suggested $C I P S$ and $C A D F$ unit root estimations, which are substantially reliable and suitable to obtain results even though the variables have the problem of cross-sectional dependence (Y. Khan et al., 2019). The simple linear equation of (Pesaran, 2007) CADF unit root can be stated as follows:

$C I \widehat{P S}=N^{-1} \sum_{i=0}^{n} C D F$

\section{Cross-sectional dependence tests}

We use cross-sectional dependence test by employing the Lagrange multiplier (LM) test developed by Breusch and Pagan (1980) and other different tests such as (CD) test developed by Hashem Pesaran and Yamagata (2008) to examine the following panel data model:

$y_{i t}=a_{i} \beta_{i}^{\prime} x_{i t}+\varepsilon_{i t} \forall i=1,2 \ldots N a n d \forall t=1,2 \ldots T$

In Eq. (4), " $T$ " denotes the time-series magnitude, $i$ denotes the cross-sectional dimension, $y_{i t}$ represents the explanatory variable, $x_{i t}$ describes the $\mathrm{I} \times \mathrm{k}$ vector of observations on the dependent variables, $a_{i}$ defines the individual intercepts, while $\beta_{i}$ represents the slope of coefficients collectively. Moreover, $\mathrm{I} \times \mathrm{k}$ and $\mathrm{I} \times \mathrm{I}$ represent the vectors of parameters to be calculated on the dependent variables that are different across $i$ (cross-sectional) and $t$ (time-series). Moreover, for every $\stackrel{\imath}{\imath} \varepsilon_{i t}$ is considered to be independently and identically distributed error terms; however, there are possibilities that the error terms could be correlated across the cross-section.

In Eq. (1), our null hypothesis $\mathrm{H}_{0}$ : we assume that there is no cross-sectional dependence alongside the alternative hypothesis $\mathrm{H}_{1}$ is as follows:

$\mathrm{H}_{0}$ : (CSD does not exist).

$\mathrm{H}_{1}$ : (CSD exists).

Based on this assumption, we employed the LM estimation in the context of dynamic seemingly unrelated regressions (DSUR) estimation, which is stated as

$L M=T \sum_{i=1}^{N-1} \sum_{j=i+1}^{N-1} \widehat{P}_{i j}^{2}$

In Eq. (5), $\widehat{P}_{\text {it }}^{2}$ represents the simple measurement of the pair-wise correlation of the residual in Eq. (1). In addition, the LM test is commonly distributed as $\mathrm{x}^{2}$ with $N(N-1) / 2$ degrees of freedom under $\mathrm{H}_{0}$, although it is not applicable where $N>T$, which proposes the subsequent scaled version of the LM estimation that is pertinent even if the number of observations $(N)$ and time $(T)$ are large.

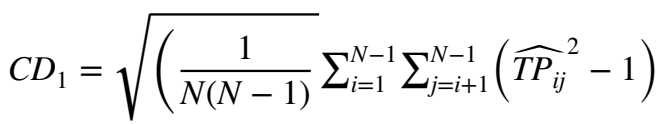

In Eq. (6), null hypothesis $\mathrm{H}: 0$ with $\mathrm{T} \rightarrow_{\infty}$ and $\mathrm{N} \rightarrow_{\infty}$ in this regard, the cross-sectional (CD) test converts to the standard normal distribution.

\section{Panel cointegration test}

The next step in our study is employing relevant econometric techniques to investigate the cointegration among all variables by using the panel cointegration estimation. For this purpose, we utilized three various statistical approaches: (1) Pedroni $(1999,2004)$ illustrated a unique technique which is distinguished as the Padroni integration estimation; (2) an approach developed by Kao (1999) is described as Kao cointegration approach; (3) Westerlund (2007a, b) proposed an error correction-based panel cointegration technique, which is the substantially suitable estimation in the cointegration evaluation. Afterward, we used the following three different cointegration estimations. As in longitudinal data series, it overcomes the issue of cross-sectional dependency and provides fair results. As our variables have the problem of CSD, we used the Westerlund's (2007a, b) cointegration test 
to figure out the problem of cross-dependency and to get more coherent outcomes. The panel cointegration estimation results are shown in Table 7.

$\boldsymbol{G}_{\mathbf{t}}=\frac{1}{N} \sum_{i-1}^{N} \frac{{ }^{\prime} \alpha_{i}}{S E\left({ }^{\prime} \alpha_{i}\right)}$

$\mathbf{G}_{\boldsymbol{\alpha}}=\frac{1}{N} \sum_{i-1}^{N} \frac{T^{\prime} \alpha_{i}}{\alpha_{i}(1)}$

$\boldsymbol{P}_{t}=\frac{\prime \alpha}{S E(\prime \alpha)}$

$\boldsymbol{P}_{a}=T \prime \alpha$

where the error correction (EC) is represented by $\dot{\alpha}$, which can be calculated by integrating $T$ and $P_{a}$ values in the above equations.

\section{Panel causality test}

We employed Hurlin and Dumitrescu (2008) to suggest a panel causality method to evaluate the causal links among all the variables. It is a revised form of the non-causality (Granger 1969) approach. According to Gorus and Aydin (2019) and Hurlin and Dumitrescu (2008), it is the most comprehensive and effective econometric technique because (a) it is more adaptable as it offers consistent outcomes nevertheless of $T>N$ or $T<N$, and (b) it is consistent for both sorts of data heterogeneous or unbalanced. This estimation is based upon Z-bar and W-bar statistics, which could be written as:

$Z_{i, t}=\alpha_{i}+\sum_{j=1}^{p} \gamma_{t}^{j} Z_{i, t-j}+\sum_{j}^{p} \gamma_{t}^{j} T_{i, t-j}$

where $\gamma_{t}^{j}$ denotes autoregressive parameters while the lag length is represented by $j$.

\section{Dynamic seemingly unrelated regression (DSUR) estimation}

This study employs dynamic seemingly unrelated regression estimation; $N$ is considered a fixed number cointegrating regression with every $T$ observation. For instance, a balanced panel is assumed as $1=1, \ldots, \mathrm{N} i=1, \ldots, N$ recorded overtime periods which is considered as $t=1, \ldots, T$.

$y_{i t}=x_{-i t}^{\prime} \beta_{-}+u_{i t}^{+}$
$\Delta x_{-i t}=e_{-i t}$

In the above equation, $x_{i t}$ considers as $\mathrm{k} \times 1$ dimensional vector.

In this section, we have employed panel cointegration estimation introduced by Westerlund (2007a, b) and Persyn and Westerlund (2008) test to encounter cross-section dependence (CSD) in the model. Table 6 illustrates the outcomes of the Westerlund ECM panel cointegration technique and further endorses the outcomes from Pedroni residual cointegration estimation in Table 7.

\section{Results and discussions}

In the discussion section, we exhibit the main outcomes of the econometric techniques in this article. Table 5 represents the unit-root test outcomes; the unit root test is an essential technique to help us understand and confirm the series of data characteristics and its suitability in the econometric analysis. In the present paper, we run $A D F$ and $P P$ tests to explore whether our data is stationary at level or first difference across the variables. Nevertheless, the estimation of the 1(1) first-order time series acknowledged the hypothesis rejection at a $1 \%$ level of significance for all data samples while it accepted the alternative hypothesis. It demonstrates that the obtained data series for all the variables are not stationary at level $1(0)$ while confirming that these variables are stationary at the first difference $1(1)$. Therefore, we can further proceed with our estimation analysis to run the related econometric techniques.*,**, and *** represent significance at $10 \%, 5 \%$, and $1 \%$ level, respectively.

Table 6 represents the long-run association correlations including all the selected variables such as the panel cointegration estimation (Joakim Westerlund 2007a, b). The key assumption of employing the cointegration test is to examine the long- and short-run association as well as confirm the validity of calculated coefficients that can be utilized for forecasting evaluation. Table 7 represents the outcomes of the Padroni residual cointegration test; in addition, we further expand for the purpose to identify the error correction term among all the selected variables. The result acknowledges that there is long-run cointegration existed among $E P U, \mathrm{CO}_{2}$ emissions, $F D I, G D P$, trade, and renewable energy consumption $(E C)$.

Table 8 represents the outcomes of cross-sectional dependence (CSD) test. The CD test results confirm the existence of cross-sectional dependence. In this case, we reject the null hypothesis of no cross-sectional dependence in all the selected variables and accept the alternative hypothesis which validates the CSD at the $1 \%$ significance level. 
Table 5 Panel unit root test

\begin{tabular}{|c|c|c|c|c|c|c|c|c|c|}
\hline & & & $\mathrm{ADF}$ & & & & PP & & \\
\hline \multirow[b]{2}{*}{ Country } & & Level & & 1st Difference & & Level & & 1st Difference & \\
\hline & & Intercept & $\begin{array}{l}\text { Trend \& Inter- } \\
\text { cept }\end{array}$ & Intercept & $\begin{array}{l}\text { Trend \& Inter- } \\
\text { cept }\end{array}$ & Intercept & $\begin{array}{l}\text { Trend \& Inter- } \\
\text { cept }\end{array}$ & Intercept & $\begin{array}{l}\text { Trend \& } \\
\text { Intercept }\end{array}$ \\
\hline \multirow[t]{8}{*}{ Japan } & $\mathrm{CO}_{2}$ & -2.89 & -2.88 & -4.61 & $-4.60 * * *$ & -3.02 & -2.98 & -5.17 & $-5.22 * * *$ \\
\hline & EPU & -3.12 & -3.01 & -6.32 & $-6.62 * * *$ & -3.05 & -2.88 & -6.47 & $-7.09 * * *$ \\
\hline & FDI & $-3.33 * *$ & -4.12 & -7.58 & $-7.39 * * *$ & -3.27 & -4.12 & -10.59 & $-10.34 * * *$ \\
\hline & GDP & -0.11 & -2.50 & -5.13 & $-5.16^{* * *}$ & 0.14 & -2.50 & -5.16 & $-5.25 * * *$ \\
\hline & Trade & -1.19 & -2.51 & -5.99 & $-5.85 * * *$ & -0.98 & -2.51 & -6.61 & $-6.55^{* * *}$ \\
\hline & $\mathrm{RE}$ & 0.97 & -0.29 & -4.64 & $-6.48 * * *$ & 2.25 & 0.52 & -4.65 & $-6.50 * * *$ \\
\hline & $\mathrm{CO}_{2}$ & -1.29 & -3.60 & -4.88 & $-4.73 * * *$ & -1.21 & -3.51 & -10.50 & $-10.50 * * *$ \\
\hline & EPU & -1.90 & -6.67 & -5.34 & $-4.99 * * *$ & -1.72 & -3.11 & -7.49 & $-7.63 * * *$ \\
\hline \multirow[t]{6}{*}{ Korea } & FDI & $-4.80 * *$ & -6.08 & -5.12 & $-4.78 * * *$ & -3.55 & -5.30 & -6.03 & $-6.18 * * *$ \\
\hline & GDP & -3.24 & -3.03 & -7.64 & $-8.53 * * *$ & -0.22 & -3.03 & -7.21 & $-7.40 * * *$ \\
\hline & Trade & -0.86 & -1.60 & -3.91 & $-3.82 * * *$ & -0.85 & -1.76 & -3.79 & $-3.67 * * *$ \\
\hline & $\mathrm{RE}$ & 1.79 & -0.72 & -4.03 & $-5.10 * * *$ & 1.77 & -0.72 & -4.02 & $-5.10 * * *$ \\
\hline & $\mathrm{CO}_{2}$ & -3.12 & -2.79 & -5.12 & $-5.46^{* * *}$ & -3.13 & -2.79 & -6.79 & $-9.14 * * *$ \\
\hline & EPU & 1.230 & -0.54 & -3.52 & $-4.06^{* * * *}$ & 1.80 & -0.45 & -3.47 & $-4.06 * * *$ \\
\hline \multirow[t]{6}{*}{ Singapore } & FDI & -5.44 & -5.37 & -5.83 & $-5.81 * * *$ & -1.99 & -1.89 & -5.83 & $-5.81 * * *$ \\
\hline & GDP & -0.07 & -2.03 & -3.23 & $-3.16^{* * *}$ & -0.07 & -1.89 & -3.24 & $-3.19 * * *$ \\
\hline & Trade & -0.44 & -4.12 & -4.63 & $-4.49 * * *$ & -0.33 & -2.95 & -4.75 & $-4.57 * * *$ \\
\hline & $\mathrm{RE}$ & -3.67 & -3.62 & -6.20 & $-6.02 * * *$ & -3.67 & -3.62 & -6.68 & $-6.46^{* * *}$ \\
\hline & $\mathrm{CO}_{2}$ & -1.05 & -3.18 & -1.43 & $-1.31 * * *$ & -0.26 & -1.82 & -1.58 & $-1.31 * * *$ \\
\hline & EPU & -0.77 & -1.94 & -4.29 & $-5.06 * * *$ & -0.58 & -0.90 & -4.29 & $-5.42 * * *$ \\
\hline \multirow[t]{4}{*}{ China } & FDI & $-1.46^{* *}$ & -2.64 & -2.71 & $-2.656^{* * *}$ & -1.01 & -1.97 & -2.74 & $-2.62 * * *$ \\
\hline & GDP & -2.58 & -3.68 & -1.23 & $-0.36^{* * *}$ & 0.53 & -1.91 & -1.92 & $-1.39 * * *$ \\
\hline & Trade & -0.147 & -3.36 & -3.87 & $-3.84 * * *$ & -0.23 & -2.36 & -3.87 & $-3.84 * * *$ \\
\hline & $\mathrm{RE}$ & -0.97 & -2.98 & -1.51 & $-1.39 * * *$ & -0.22 & -1.85 & -1.66 & $-1.47 * * *$ \\
\hline
\end{tabular}

Table 6 Westerlund ECM panel cointegration tests

\begin{tabular}{llll}
\hline Statistic & Value & $z$ value & $p$ value \\
\hline $\mathrm{Gt}$ & $-1.851^{* *}$ & -1.682 & 0.04 \\
$\mathrm{Ga}$ & -2.078 & 0.758 & 0.77 \\
$\mathrm{Pt}$ & $-3.464^{* *}$ & -2.093 & 0.01 \\
$\mathrm{~Pa}$ & $-4.531^{* * *}$ & -2.421 & 0.00 \\
\hline
\end{tabular}

$*$, **, and $* * *$ represent significance at $10 \%, 5 \%$, and $1 \%$ level, respectively.

Table 9 represents the outcomes of the panel Granger causality test, we found that there is a one-way Granger causality running from $\mathrm{EPU}$ to $\mathrm{CO}_{2}$ emissions, which indicates that it increases the level of $\mathrm{CO}_{2}$ emissions in the East Asian countries. In the context of $F D I$, a two-way causality links between $\mathrm{FDI}$ inflows and $\mathrm{CO}_{2}$ emissions. The more $\mathrm{FDI}$ inflow attracts these four countries, the more it will accelerate to mitigate the level of $\mathrm{CO}_{2}$ emissions. However, some research scholars such as Haug and Ucal (2019) and Zhang and Zhou (2016) found that FDI inflows play a substantial
Table 7 Pedroni residual cointegration test

\begin{tabular}{llllll}
\hline Within dimension & & & & \\
& & & & \multicolumn{2}{l}{ Weighted } \\
\cline { 5 - 6 } \cline { 5 - 6 } & Statistic & Prob & & Statistic & Prob \\
\hline Panel v-Statistic & -0.2039 & 0.5808 & -2.1390 & 0.9838 \\
Panel rho-Statistic & 1.6863 & 0.9541 & 1.5703 & 0.9418 \\
Panel PP-Statistic & -0.1383 & 0.4450 & -4.2357 & $0.000^{* * *}$ \\
Panel ADF-Statistic & 0.7062 & 0.7600 & -2.5346 & $0.005^{* *}$ \\
Between dimension & & & & \\
& & Statistic & Prob & & \\
Group rho-Statistic & 2.3764 & 0.9913 & & \\
Group PP-Statistic & -6.9346 & $0.000^{* * *}$ & & \\
Group ADF-Statistic & -1.9009 & $0.028^{* *}$ & & \\
\hline
\end{tabular}

$*$, **, and *** represent significance at $10 \%, 5 \%$, and $1 \%$ level, respectively.

role in mitigating $\mathrm{CO}_{2}$ emissions. In addition, a two-way Granger causality was found between economic growth and $\mathrm{CO}_{2}$ emissions. It indicates that an increase in per capita 
Table 8 Cross-sectional dependence tests

\begin{tabular}{lr}
\hline Test & Statistic \\
\hline Breusch-Pagan, LM & $28.218^{* * * *}$ \\
Pesaran scaled, LM & $6.4140^{* * * *}$ \\
Pesaran, CD & $-3.5098 * * *$ \\
\hline$*, * *$, and $* * *$ represent significance at $10 \%, 5 \%$, and $1 \%$ level, \\
respectively.
\end{tabular}

of renewable energy consumption (i.e., wind energy, solar energy, hydroelectric energy) significantly reduces the level of $\mathrm{CO}_{2}$ emissions.

Table 10 represents the outcomes of panel dynamic seemingly unrelated regression (DSUR). Based on the outcomes, the regression coefficient of economic policy uncertainty (EPU) shows a positive and significant correlation at the $10 \%$ level of significance. This outcome illustrates that uncertainty in economic policy can increase $\mathrm{CO}_{2}$ emis-

Table 9 Granger causality test

\begin{tabular}{lllllll}
\hline & $\mathrm{CO}_{2}$ & EPU & FDI & GDP & Trade & RE \\
\hline $\mathrm{CO}_{2}$ & & 3.271 & 4.590 & 10.141 & 2.676 & 0.844 \\
& & $(2.523)^{* *}$ & $(1.792)^{* *}$ & $(10.547)^{*}$ & $(1.827)^{* *}$ & $(-0.311)$ \\
EPU & 1.182 & & 2.392 & 2.364 & 0.598 & 3.609 \\
& $(0.083)^{* *}$ & & $(0.097)^{*}$ & $(1.463)$ & $(-5.997)$ & $(1.094)^{* *}$ \\
FDI & 12.366 & 2.052 & & 7.426 & 1.176 & 9.296 \\
& $(13.146)^{*}$ & $(1.100)$ & & $(7.376)^{*}$ & $(0.075)^{* *}$ & $(9.560)^{*}$ \\
GDP & 5.172 & 3.181 & 4.688 & & 1.580 & 6.602 \\
& $(4.747)^{*}$ & $(2.414)^{* *}$ & $(1.868)^{* *}$ & & $(7.483)^{* *}$ & $(6.413)^{*}$ \\
Trade & 2.551 & 3.154 & 2.146 & 1.440 & & 1.562 \\
& $(1.682)^{* *}$ & $(2.386)^{* *}$ & $(-0.093)$ & $(0.384)^{*}$ & & $(0.527)^{*}$ \\
EC & 2.048 & 3.019 & 4.992 & 8.409 & 2.331 & \\
& $(1.094)^{*}$ & $(2.229)^{* *}$ & $(2.103)^{* *}$ & $(8.524)^{*}$ & $(1.422)^{* *}$ & \\
\hline
\end{tabular}

$*, * *$, and $* * *$ represent significance at $10 \%, 5 \%$, and $1 \%$ level, respectively.

Table 10 Results of panel dynamic seemingly unrelated regression (DSUR)

\begin{tabular}{llll}
\hline $\begin{array}{l}\text { Response variable: } \mathrm{CO}_{2} \\
\text { emissions }\end{array}$ & & & \\
\hline Variables & Coef & $t$ value & $p$ value \\
EPU & $0.1599^{* * *}$ & 3.65 & 0.000 \\
EC & $-0.1144^{* * *}$ & -4.23 & 0.000 \\
FDI & $-0.0395^{* *}$ & -3.16 & 0.002 \\
GDP & $0.2648^{* * *}$ & 8.14 & 0.000 \\
Trade & $0.0174^{* * *}$ & 0.65 & 0.051 \\
Constant & $-0.6976^{* *}$ & -1.23 & 0.021 \\
$R^{2}$ & 0.69 & & \\
F-state & 195.19 & & \\
Prob & 0.0000 & & \\
\hline
\end{tabular}

$*$, **, and $* * *$ represent significance at $10 \%, 5 \%$, and $1 \%$ level, respectively.

income will lead to an increase in carbon emissions in these countries. It has been widely acknowledged by researchers that countries going through an economic growth cycle will ultimately contribute to a significant portion of $\mathrm{CO}_{2}$ emissions. Similarly, we found a one-way Granger causality link between $\mathrm{CO}_{2}$ emissions and trade openness, indicating that trade openness could help in reducing $\mathrm{CO}_{2}$ emissions. Finally, a one-way Granger causality association was found between $E C$ and $\mathrm{CO}_{2}$ emissions. It indicates that the use sions in the East Asian region. The regression coefficient of renewable energy consumption is a negative but significant connection with $\mathrm{CO}_{2}$ emissions, indicating that the use of renewable energy consumption declines carbon emissions. Similarly, we found a negative but significant correlation between carbon emissions and FDI indicating that FDI can play a tremendous involvement in declining carbon emissions. Moreover, economic growth shows a positive and significant relationship with $\mathrm{CO}_{2}$ emissions at the $5 \%$ level. The positive relationship demonstrates that the role of economic growth is inevitable in mitigating $\mathrm{CO}_{2}$ emissions. Likewise, the regression coefficient of trade openness shows a positive and significant relationship with $\mathrm{CO}_{2}$ emissions at the $1 \%$ level of significance.

The findings obtained from $P M G, M G$, and dynamic fixed-effects models are shown in Table 11. The results confirm a long-run relationship between economic policy uncertainty, $\mathrm{CO}_{2}$ emissions, $\mathrm{FDI}$, trade, economic growth, and renewable energy consumption. Moreover, we determined a negative but significant relationship between the dependent variable $\mathrm{CO}_{2}$ emissions and independent variables renewable energy consumption (EC) and trade openness (Trade). On the other hand, a positive and significant connection was found between $\mathrm{CO}_{2}$ emissions, $E P U, F D I$, and $G D P$.

Table 12 shows the outcomes of the robustness check, we used fully modified OLS and dynamic OLS to examine 
Table 11 The outcomes of long-run estimation PMG, MG, and dynamic fixed effect

\begin{tabular}{|c|c|c|c|c|c|c|}
\hline & \multicolumn{2}{|c|}{ PMG estimation } & \multicolumn{2}{|c|}{ MG estimation } & \multicolumn{2}{|c|}{ DFE estimation } \\
\hline & Coef & $z$ value & Coef & $z$ value & Coef & $z$ value \\
\hline \multicolumn{7}{|c|}{ Dependent variable: $\mathrm{CO}_{2}$ emissions } \\
\hline EPU & $0.027 * *$ & 1.82 & $0.061 * * *$ & 2.79 & $-0.619 * *$ & -1.38 \\
\hline $\mathrm{EC}$ & $-0.303 * * *$ & -7.89 & $-0.394 * * *$ & -5.04 & $0.481 * *$ & 1.17 \\
\hline FDI & $0.039 * * *$ & 5.37 & $0.030 * * *$ & 4.14 & $0.057 * *$ & 0.25 \\
\hline GDP & $0.661 * * *$ & 9.76 & $1.184 * * *$ & 3.68 & $0.022 * *$ & 0.04 \\
\hline Trade & $-0.049 * *$ & -2.66 & $-0.129 * * *$ & -2.94 & $0.206^{* * *}$ & 0.73 \\
\hline
\end{tabular}

$*, * *$, and $* * *$ represent significance at $10 \%, 5 \%$, and $1 \%$ level, respectively.

Table 12 Robustness test

\begin{tabular}{|c|c|c|c|c|c|c|c|c|c|c|}
\hline \multicolumn{2}{|c|}{ Full sample } & \multirow[b]{2}{*}{$t$ value } & \multirow{2}{*}{$\begin{array}{l}\text { Japan } \\
\text { Coef }\end{array}$} & \multirow[b]{2}{*}{$t$ value } & \multirow{2}{*}{$\begin{array}{l}\text { Korea } \\
\text { Coef }\end{array}$} & \multirow[b]{2}{*}{$t$ value } & \multirow{2}{*}{$\begin{array}{l}\text { China } \\
\text { Coef }\end{array}$} & \multirow[b]{2}{*}{$t$ value } & \multicolumn{2}{|l|}{ Singapore } \\
\hline Variable & Coef & & & & & & & & Coef & $t$ value \\
\hline EPU & $0.16 * * *$ & 1.70 & $0.00 * * *$ & 3.25 & $0.52 * * *$ & 11.51 & $0.00 * * *$ & 4.90 & $0.52 * * *$ & 10.18 \\
\hline $\mathrm{EC}$ & -0.09 & -1.26 & $-0.64 * * *$ & -6.01 & $0.59 * * *$ & 6.62 & $0.00 * * *$ & 25.29 & $0.59 * * *$ & 5.86 \\
\hline FDI & $-0.02 *$ & -0.96 & $8.76 \mathrm{E}-12 * *$ & 2.61 & $0.63 * *$ & 5.91 & $0.00 * * *$ & 1.86 & $0.63 * * *$ & 5.23 \\
\hline GDP & $0.26^{*}$ & 4.98 & $0.00 * * *$ & 4.44 & $-0.43^{*}$ & -3.65 & $-1.53 \mathrm{E}-05^{* * *}$ & -0.90 & $-0.43 * *$ & -3.23 \\
\hline TRADE & $-0.01 *$ & -0.76 & $-1.67 \mathrm{E}-* * *$ & -3.95 & $-0.11 * *$ & -1.79 & $-3.77 \mathrm{E}-13 * *$ & -2.43 & $-0.11 * *$ & -1.58 \\
\hline$R^{2}$ & 0.72 & & 0.35 & & 0.13 & & 0.99 & & 0.19 & \\
\hline
\end{tabular}

$*, * *$, and $* * *$ represent significance at $10 \%, 5 \%$, and $1 \%$ level, respectively.

\section{Inverse Roots of AR Characteristic Polynomial}

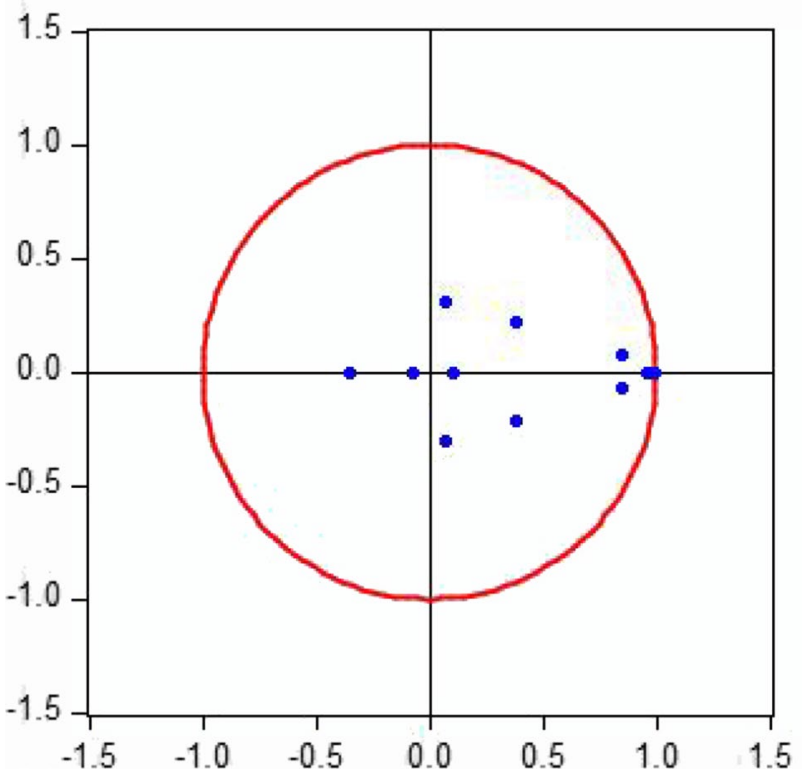

Fig. 6 Representation of inverse roots of AR characteristics polynomial

the regression coefficients of all the response and explanatory variables. The test confirms that there is no variation in the coefficients of $E P U, \mathrm{CO}_{2}$ emissions, $F D I$, trade, $G D P$, trade, and renewable energy consumption. Furthermore, the

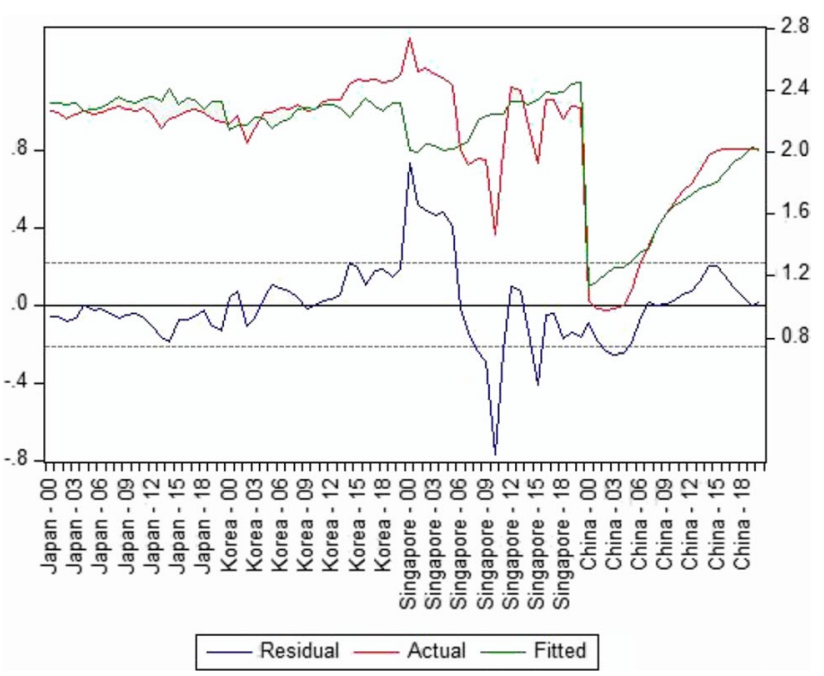

Fig. 7 Visualization of the residual, actual, and fitted values of the observed countries

FMOLS estimation was utilized for robustness check, and it found that our results are robust and consolidate. Finally, Fig. 6 illustrates the validation of the econometric model panel dynamic seemingly unrelated regression (DUSR), indicating that the model is best fitted in investigating the association between $\mathrm{CO}_{2}$ emissions, $E P U, F D I$, trade, economic growth, and renewable energy consumption. We further investigated the relationship between these variables by 
drawing Fig. 7. It shows that all the variables' residuals are fitted around the slope line.

In Table 10, we obtain the results from panel dynamic seemingly unrelated test which point out a positive association of $E P U, G D P$, and trade openness with $\mathrm{CO}_{2}$ emissions, which validate that an increase in these explanatory variables will reduce environmental quality. However, renewable energy $(R E)$ and $F D I$ show a negative and significant relationship with $\mathrm{CO}_{2}$ emissions, which signifies that $\mathrm{FDI}$ and renewable energy boost the environment quality.

\section{Fully modified ordinary least square (FMOLS).}

In this section, we employed the fully modified (OLS) estimation approach to explore the dynamic influence of EPU on $\mathrm{CO}_{2}$ emissions along with other control repressors.

$\ln C O_{2 t}=\beta_{0}+\beta_{1} \ln X_{t}+\varepsilon_{t}$

In Eq. (14), $\ln C \mathrm{O}_{2 t}$ is the dependent variable, $\beta_{0}$ represents the intercept, while $\beta_{1}$ defines the vector slope coefficients; $\ln X_{t}$ describes the vector of response variables including economic policy uncertainty $(E P U)$. Finally, $\varepsilon_{t}$ represents the error term in the equation. In addition, for robustness check, we utilized FMOLS estimation developed by Phillips and Hansen (1990); the purpose of employing FMOLS is to reacquire the indifferent estimators of cointegrating estimations based on the single equation. Fundamentally, the FMOLS technique distorts OLS to distinguish the implicit endogeneity bias error. Moreover, FMOLS copes with the problem of serial correlation, as well as the FMOLS method which is asymptotically implicit and significantly efficient and effective in the existence of mixture normal asymptotic.

The results from FMOLS estimation are tabulated in Table 12. It illustrates that economic policy uncertainty ( $E P U$ ) shows a positive and significant association with $\mathrm{CO}_{2}$ emissions in the case of a full sample. This demonstrates that $E P U$ has a remarkable influence on $\mathrm{CO}_{2}$ emissions. The findings also synchronize with the previous study of Pirgaip and Dinçergök (2020a). Furthermore, trade openness, energy consumption, and $F D I$ have a negative coefficient but insignificant in the full sample, while a positive and significant coefficient of GDP illustrates that it is helpful for the degradation of $\mathrm{CO}_{2}$ emissions.

\section{Conclusion and policy recommendation}

Economic policy uncertainty has received substantial attention since the great recession period from 2007 to 2009 . Since then, research scholars have developed two panoramic proclaims: in the first claim, scholars urged that EPU has raised since the breakthrough of recession. Second, this economic uncertainty prevented repossession. This study explores the links between $E P U, F D I$, energy consumption (EC), GDP, trade, and $\mathrm{CO}_{2}$ emissions for the panel of four advanced developing economies from 1997 to 2020. For reliable outcomes, we employ second-generation econometric methods to check cross-sectional dependency, stationary, and cointegration among variables. In addition, we employ the DSUR estimation to examine the long-run association as well as the D-H panel causality estimation to confirm the Granger causality links between the selected variables. Moreover, we also use the FMOLS and DOLS models for robustness checks. We figured out that $E P U, G D P$, and trade have a negative effect on the environment, while $F D I$ indicates a positive effect and thus improves the performance of the environment of these four developing economies. The main findings show that a $1 \%$ increase in $G D P, E P U$, and trade effect $0.1870,0.1548$, and $0.0562 \%$ increases in the mitigation of the environment at $1 \%$ and $5 \%$ significant levels. Regardless, a $1 \%$ increase in $F D I$ is associated with a $0.0048 \%$ reduction in $\mathrm{CO}_{2}$ emission at a $5 \%$ significant level. The results of the D-H panel causality method revealed a two-way association between $\mathrm{CO}_{2}$ and economic policy uncertainty, $\mathrm{CO}_{2}$ and renewable energy consumption, $\mathrm{CO}_{2}$ and economic growth, $\mathrm{CO}_{2}$, and trade. However, one-way causality is running from economic policy uncertainty to trade, $F D I$ to $\mathrm{CO}_{2}, F D I$ to energy consumption, $\mathrm{FDI}$ to economic growth, and $F D I$ to trade.

The study has a great significance specifically for governments and policymakers to deduce the landscape and dynamics of the country/region in designing economic policies about the possibility of economic policy uncertainty and mitigating $\mathrm{CO}_{2}$ emissions. Besides, these policies should be planned beyond deterring policy stability, as $E P U$ can induce adverse environmental issues. Consequently, it is suggested that the governments or decision-makers of the four developing countries should impose policies to decrease the energy usage and to upsurge the level of clean energy resources in a way that delivers comprehensive assistance to economic affluence, which in turn would mitigate economic policy uncertainty. In addition, the meaningful policies would helm significant time to levy; besides, these four advanced economies are esoterically developing at a rapid pace. Furthermore, they have the rich resources to headway toward a green and clean sustainable environment. Nevertheless, this study finds some new insights on the relationship between $E P U, \mathrm{CO}_{2}, F D I, E C, G D P$, and trade so far. The present paper employed a panel of four advanced economies, namely, Singapore, Japan, South Korea, and China. Hence, future studies should consider a region/global sample to investigate the effect of $E P U, F D I, R E, G D P$, and trade on $\mathrm{CO}_{2}$ emissions. It will give a better understanding and provide some latest insights regarding enhancing environmental quality in a specific country/region. 


\section{Declarations}

Ethical approval. We confirmed that this manuscript has not been published elsewhere and is not under consideration by another journal. Ethical approval and informed consent do not apply to this study.

Consent to participate Not applicable.

Consent to publish Not applicable.

Author contribution The idea of the original draft belongs to Y.K.; he wrote the introduction, literature review, and empirical outcomes sections. Z.X. and C.S. helped in data collection and data compiling. D.K. visualized data of observed variables. T.H. constructed the methodology section and revised the final draft. All the authors read and approved the final manuscript.

Conflict of interest The authors declare no competing interests.

Funding This study is financially supported by the Research Program of Social Science and Humanities, Ministry of Higher Education (21YJA790081).

Foundation of Anhui Natural Science project number (2108085MG245).

Data availability statement The data for this study is available on World Bank (WB) and BP Statistical Review websites. The data used in this study is from 1997 to 2020 . The missing data for the last 2 years were generated based on previous data for some countries.

\section{References}

Abbasi KR, Adedoyin FF (2021) Do energy use and economic policy uncertainty affect $\mathrm{CO} 2$ emissions in China? Empirical evidence from the dynamic ARDL simulation approach. Environ Sci Pollut Res 28(18):23323-23335

Abdouli M, Hammami S (2017) Investigating the causality links between environmental quality, foreign direct investment and economic growth in MENA countries. Int Bus Rev 26(2):264-278

Adams S, Klobodu EKM, Apio A (2018) Renewable and non-renewable energy, regime type and economic growth. Renewable Energy 125:755-767. https://doi.org/10.1016/j.renene.2018.02.135

Adams S, Adedoyin F, Olaniran E, Bekun FV (2020) Energy consumption, economic policy uncertainty and carbon emissions; causality evidence from resource rich economies. Economic Anal Polic 68:179-190

Adedoyin FF, Zakari A (2020) Energy consumption, economic expansion, and $\mathrm{CO} 2$ emission in the UK: the role of economic policy uncertainty. Sci Total Environ 738:140014

Al-mulali U (2012) Factors affecting CO2 emission in the Middle East: a panel data analysis. Energy 44(1):564-569

Al-Mulali U, Tang CF (2013) Investigating the validity of pollution haven hypothesis in the Gulf Cooperation Council (GCC) countries. Energy Policy 60:813-819

Alola AA, Bekun FV, Sarkodie SA (2019) Dynamic impact of trade policy, economic growth, fertility rate, renewable and non-renewable energy consumption on ecological footprint in Europe. Sci Total Environ 685:702-709

Al-Thaqeb SA, Algharabali BG (2019) Economic policy uncertainty: a literature review. J Econ Asymmetr 20:e00133
Altig D, Baker S, Barrero JM, Bloom N, Bunn P, Chen S et al (2020) Economic uncertainty before and during the COVID-19 pandemic. J Public Econ 191:104274

Andreoni V, Galmarini S (2012) Decoupling economic growth from carbon dioxide emissions: a decomposition analysis of Italian energy consumption. Energy 44(1):682-691. https://doi.org/10. 1016/j.energy.2012.05.024

Anser MK, Apergis N, Syed QR (2021) Impact of economic policy uncertainty on $\mathrm{CO} 2$ emissions: evidence from top ten carbon emitter countries. Environ Sci Pollut Res 28(23):29369-29378

Apergis N, Payne JE (2010) The emissions, energy consumption, and growth nexus: evidence from the commonwealth of independent states. Energy Policy 38(1):650-655. https://doi.org/10.1016/j. enpol.2009.08.029

Appiah MO (2018) Investigating the multivariate Granger causality between energy consumption, economic growth and $\mathrm{CO} 2$ emissions in Ghana. Energy Policy 112:198-208

Asiedu E (2006) Foreign direct investment in Africa: the role of natural resources, market size, government policy, institutions and political instability. World Economy 29(1):63-77

Atici C (2012) Carbon emissions, trade liberalization, and the JapanASEAN interaction: a group-wise examination. J Japan Int Econ 26(1):167-178

Baek J (2015) A panel cointegration analysis of CO2 emissions, nuclear energy and income in major nuclear generating countries. Appl Energy 145:133-138

Baek J (2016) A new look at the FDI-income-energy-environment nexus: dynamic panel data analysis of ASEAN. Energy Policy 91:22-27

Baker SR, Bloom N, Davis SJ (2016) Measuring economic policy uncertainty*. Q J Econ 131(4):1593-1636. https://doi.org/10. 1093/qje/qjw024

Baker SR, Bloom N, Davis SJ, and Terry SJ (2020). Covid-induced economic uncertainty (0898-2937). Retrieved from

Bekun FV, Emir F, Sarkodie SA (2019) Another look at the relationship between energy consumption, carbon dioxide emissions, and economic growth in South Africa. Sci Total Environ 655:759-765

Bernal O, Gnabo J-Y, Guilmin G (2016) Economic policy uncertainty and risk spillovers in the Eurozone. J Int Money Financ 65:24-45

Bernanke BS (1983) Irreversibility, uncertainty, and cyclical investment. Q J Econ 98(1):85-106. https://doi.org/10.2307/1885568

Blattman C, Miguel E (2010) Civil War. J Econ Lit 48(1):3-57

Bonaime A, Gulen H, Ion M (2018) Does policy uncertainty affect mergers and acquisitions? J Financ Econ 129(3):531-558

Boutabba MA (2014) The impact of financial development, income, energy and trade on carbon emissions: evidence from the Indian economy. Econ Model 40:33-41. https://doi.org/10.1016/j.econm od.2014.03.005

BP Statistics (2020).

Breusch TS, Pagan AR (1980) The Lagrange multiplier test and its applications to model specification in econometrics. Rev Econ Stud 47(1):239-253. https://doi.org/10.2307/2297111

Copeland BR, Taylor MS (1994) North-South trade and the environment. Q J Econ 109(3):755-787

Ehigiamusoe KU, Lean HH (2019) Effects of energy consumption, economic growth, and financial development on carbon emissions: evidence from heterogeneous income groups. Environ Sci Pollut Res 26(22):22611-22624

Friedman M (1995) The role of monetary policy. In: Estrin S, Marin A (eds) Essential readings in economics. Macmillan Education UK, London, pp 215-231

Gorus MS, Aydin M (2019) The relationship between energy consumption, economic growth, and $\mathrm{CO} 2$ emission in MENA countries: causality analysis in the frequency domain. Energy 168:815-822 
Guidolin M, La Ferrara E (2010) The economic effects of violent conflict: evidence from asset market reactions. J Peace Res 47(6):671-684

Gulen H, Ion M (2016) Policy uncertainty and corporate investment. Rev Financ Stud 29(3):523-564

Halicioglu F (2009) An econometric study of CO2 emissions, energy consumption, income and foreign trade in Turkey. Energy Policy 37(3):1156-1164

Handley K, Limao N (2017) Policy uncertainty, trade, and welfare: theory and evidence for China and the United States. Am Econ Rev 107(9):2731-2783

Hao Y, Wu Y, Wu H, Ren S (2020) How do FDI and technical innovation affect environmental quality? Evidence from China. Environ Sci Pollut Res 27(8):7835-7850

Hashem Pesaran M, Yamagata T (2008) Testing slope homogeneity in large panels. J Econometr 142(1):50-93. https://doi.org/10.1016/j. jeconom.2007.05.010

Hassan T, Song H, Kirikkaleli D (2021) International trade and consumption-based carbon emissions: evaluating the role of composite risk for RCEP economies. Environ Sci Pollut Res 1:1-21

Haug AA, Ucal M (2019) The role of trade and FDI for CO2 emissions in Turkey: nonlinear relationships. Energy Econ 81:297-307

Hurlin C, Dumitrescu E (2008) Testing for Granger non causality in heterogeneous panels. Depart Econ 29:1450-1460

Jahangir Alam M, Ara Begum I, Buysse J, Van Huylenbroeck G (2012) Energy consumption, carbon emissions and economic growth nexus in Bangladesh: cointegration and dynamic causality analysis. Energy Policy 45:217-225. https://doi.org/10.1016/j.enpol. 2012.02.022

Jiang Y, Zhou Z, Liu C (2019) Does economic policy uncertainty matter for carbon emission? Evidence from US sector level data. Environ Sci Pollut Res 26(24):24380-24394

Jin Guanghui LZHG (2016) Policy uncertainty and corporate investment: an empirical study on strategic and emerging industry. Manage Rev 28(9):3-16

Junttila J, Vataja J (2018) Economic policy uncertainty effects for forecasting future real economic activity. Econ Syst 42(4):569-583

Kao C (1999) Spurious regression and residual-based tests for cointegration in panel data. J Econometr 90(1):1-44

Khan Y, Bin Q (2020) The environmental Kuznets curve for carbon dioxide emissions and trade on belt and road initiative countries: a spatial panel data approach. Singapore Econ Rev 65(04):10991126. https://doi.org/10.1142/s0217590819500255

Khan Y, Bin Q, Hassan T (2019) The impact of climate changes on agriculture export trade in Pakistan: evidence from time-series analysis. Growth Chang 50(4):1568-1589

Khan Z, Ali M, Kirikkaleli D, Wahab S, Jiao Z (2020a) The impact of technological innovation and public-private partnership investment on sustainable environment in China: consumption-based carbon emissions analysis. Sustain Dev 28(5):1317-1330. https:// doi.org/10.1002/sd.2086

Khan Z, Ali S, Umar M, Kirikkaleli D, Jiao Z (2020b) Consumptionbased carbon emissions and international trade in $\mathrm{G} 7$ countries: the role of environmental innovation and renewable energy. Sci Total Environ 730:138945. https://doi.org/10.1016/j.scitotenv. 2020.138945

Khan I, Hou F, Zakari A, Tawiah VK (2021) The dynamic links among energy transitions, energy consumption, and sustainable economic growth: a novel framework for IEA countries. Energy 222:119935

Khan Y, ShuKai C, Hassan T, Kootwal J, Khan MN (2021b) The links between renewable energy, fossil energy, terrorism, economic growth and trade openness: the case of Pakistan. SN Bus Econ 1(9):115. https://doi.org/10.1007/s43546-021-00112-2

Kim MH, Adilov N (2012) The lesser of two evils: an empirical investigation of foreign direct investment-pollution tradeoff. Appl Econ 44(20):2597-2606
Liu G, Zhang C (2020) Economic policy uncertainty and firms' investment and financing decisions in China. China Econ Rev 63:101279. https://doi.org/10.1016/j.chieco.2019.02.007

Long Y, Yoshida Y, Zhang H, Zheng H, Shan Y, Guan D (2020) Japan prefectural emission accounts and socioeconomic data 2007 to 2015. Scientific Data 7(1):1-8

Marcotullio PJ, Sarzynski A, Albrecht J, Schulz N (2012) The geography of urban greenhouse gas emissions in Asia: a regional analysis. Glob Environ Chang 22(4):944-958

Mert M, Bölük G (2016) Do foreign direct investment and renewable energy consumption affect the $\mathrm{CO} 2$ emissions? New evidence from a panel ARDL approach to Kyoto Annex countries. Environ Sci Pollut Res 23(21):21669-21681

Mielnik O, Goldemberg J (2002) Foreign direct investment and decoupling between energy and gross domestic product in developing countries. Energy Policy 30(2):87-89

Ozturk I (2010) A literature survey on energy-growth nexus. Energy Policy 38(1):340-349. https://doi.org/10.1016/j.enpol.2009.09. 024

Pao H-T, Tsai C-M (2011) Multivariate Granger causality between $\mathrm{CO} 2$ emissions, energy consumption, FDI (foreign direct investment) and GDP (gross domestic product): evidence from a panel of BRIC (Brazil, Russian Federation, India, and China) countries. Energy 36(1):685-693

Pedroni P (1999) Critical values for cointegration tests in heterogeneous panels with multiple regressors. Oxford Bull Econ Stat 61(S1):653-670

Pedroni P (2004) Panel cointegration: asymptotic and finite sample properties of pooled time series tests with an application to the PPP hypothesis. Econometr Theory 20:597-625

Persyn D, Westerlund J (2008) Error-correction-based cointegration tests for panel data. Stand Genomic Sci 8(2):232-241

Pesaran MH (2007) A simple panel unit root test in the presence of cross-section dependence. J Appl Economet 22(2):265-312

Phillips PCB, Hansen BE (1990) Statistical inference in instrumental variables regression with $\mathrm{I}(1)$ processes. Rev Econ Stud 57(1):99-125. https://doi.org/10.2307/2297545

Pirgaip B, Dinçergök B (2020a) Economic policy uncertainty, energy consumption and carbon emissions in G7 countries: evidence from a panel Granger causality analysis. Environ Sci Pollut Res 27(24):30050-30066. https://doi.org/10.1007/ s11356-020-08642-2

Pirgaip B, Dinçergök B (2020b) Economic policy uncertainty, energy consumption and carbon emissions in G7 countries: evidence from a panel Granger causality analysis. Environ Sci Pollut Res 27:30050-30066

Rigobon R, Sack B (2005) The effects of war risk on US financial markets. J Bank Finance 29(7):1769-1789

Rodrik D (1991) Policy uncertainty and private investment in developing countries. J Dev Econ 36(2):229-242. https://doi.org/10. 1016/0304-3878(91)90034-S

Sabir S, Qayyum U, Majeed T (2020) FDI and environmental degradation: the role of political institutions in South Asian countries. Environ Sci Pollut Res 27(26):32544-32553

Shaari MS, Hussain NE, Abdullah H, Kamil S (2014) Relationship among foreign direct investment, economic growth and CO2 emission: a panel data analysis. Int J Energy Econ Polic 4(4):706

Shahbaz M, Nasreen S, Ahmed K, Hammoudeh S (2017a) Trade openness-carbon emissions nexus: the importance of turning points of trade openness for country panels. Energy Econ 61:221-232

Shahbaz M, Solarin SA, Hammoudeh S, Shahzad SJH (2017b) Bounds testing approach to analyzing the environment Kuznets curve hypothesis with structural beaks: the role of biomass energy consumption in the United States. Energy Econ 68:548-565 
Shahbaz M, Zakaria M, Shahzad SJH, Mahalik MK (2018) The energy consumption and economic growth nexus in top ten energy-consuming countries: fresh evidence from using the quantile-onquantile approach. Energy Econ 71:282-301

Shahbaz M, Balsalobre-Lorente D, Sinha A (2019) Foreign direct investment-CO2 emissions nexus in Middle East and North African countries: importance of biomass energy consumption. $\mathrm{J}$ Clean Prod 217:603-614. https://doi.org/10.1016/j.jclepro.2019. 01.282

Shan Y, Guan D, Zheng H, Ou J, Li Y, Meng J, Zhang Q et al (2018) China CO2 emission accounts 1997-2015. Scientific Data 5(1):1-14

Sun L, Liu W, Li Z, Cai B, Fujii M, Luo X, Le Y et al (2021) Spatial and structural characteristics of $\mathrm{CO} 2$ emissions in East Asian megacities and its indication for low-carbon city development. Appl Energy 284:116400. https://doi.org/10.1016/j.apenergy. 2020.116400

Tang CF, Tan BW (2015) The impact of energy consumption, income and foreign direct investment on carbon dioxide emissions in Vietnam. Energy 79:447-454

Telias D, and Urdinez F (2020). China's foreign aid political drivers: lessons from a novel dataset of mask diplomacy in Latin America during the COVID-19 pandemic. J Curr Chin Affairs.

Walter I, Ugelow JL (1979) Environmental policies in developing countries. Ambio 1:102-109

Wang Q, Xiao K, Lu Z (2020) Does economic policy uncertainty affect $\mathrm{CO} 2$ emissions? Empirical evidence from the United States. Sustainability 12(21):9108
Westerlund J (2007a) Error correction based panel cointegration tests. Oxford Bull Econ Stat 69:709-748

Westerlund $\mathbf{J}$ (2007b) Testing for error correction in panel data. Oxford Bull Econ Stat 69(6):709-748

World Bank Indicator. (2020).

Yang F, Li Y, Xu J (2016) Review on urban GHG inventory in China. Int Rev Spat Plan Sustain Dev 4(2):46-59

Yang B, Ali M, Hashmi SH, Shabir M (2020) Income inequality and $\mathrm{CO} 2$ emissions in developing countries: the moderating role of financial instability. Sustainability 12(17):6810

Yu J, Shi X, Guo D, Yang L (2021) Economic policy uncertainty (EPU) and firm carbon emissions: evidence using a China provincial EPU index. Energy Economics 94:105071

Zhang Y, Zhang S (2018) The impacts of GDP, trade structure, exchange rate and FDI inflows on China's carbon emissions. Energy Policy 120:347-353

Zhang C, Zhou X (2016) Does foreign direct investment lead to lower $\mathrm{CO} 2$ emissions? Evidence from a regional analysis in China. Renew Sustain Energy Rev 58:943-951. https://doi.org/10.1016/j. rser.2015.12.226

Zomorrodi A, Zhou X (2017) Impact of FDI on environmental quality of China. Int J Bus Econ Manag 4(1):1-15

Publisher's Note Springer Nature remains neutral with regard to jurisdictional claims in published maps and institutional affiliations. 